US Army Corps

of Engineers ${ }_{\circledast}$

Engineer Research and

Development Center

ERDC Technology Transfer and Infusion/Knowledge Management

\title{
Discover ERDC Knowledge Management Representative (KMR) User's Guide
}

Byron M. Garton, Jonathan S. Broderick,

September 2020 and Michael A. Clement 
The U.S. Army Engineer Research and Development Center (ERDC) solves the nation's toughest engineering and environmental challenges. ERDC develops innovative solutions in civil and military engineering, geospatial sciences, water resources, and environmental sciences for the Army, the Department of Defense, civilian agencies, and our nation's public good. Find out more at www.erdc.usace.army.mil.

To search for other technical reports published by ERDC, visit the ERDC online library at https://erdclibrary.on.worldcat.org/discovery. 


\section{Discover ERDC Knowledge Management Representative (KMR) User's Guide}

Byron M. Garton, Jonathan S. Broderick, and Michael A. Clement

Information Technology Laboratory

U.S. Army Engineer Research and Development Center

3909 Halls Ferry Road

Vicksburg, MS 39180-6199

Final report

Approved for public release; distribution is unlimited.

Prepared for ERDC Office of Research and Technology Transfer (ORTT)

3909 Halls Ferry Road

Vicksburg, MS 39180-6199

Under ERDC Office of Research and Technology Transfer (ORRT), MIPR WIC 19F1H5 


\section{Abstract}

Knowledge management plays a vital role in the successful execution on research projects at the U.S. Army Engineer Research and Development Center (ERDC). Accumulating and building upon knowledge is the cornerstone of the research and development process. Maintaining and providing access to knowledge is essential to the successful execution of research programs. An initiative to improve access to knowledge and the tools available to researchers was started by the Office of Research and Technology Transfer (ORRT). The result of that initiative is a knowledge portal called Discover ERDC.

This document provides a detailed look on maintaining content on the Discover ERDC site from a Knowledge Management Representative viewpoint, and how help can be provided to those assigned to manage the content.

DISCLAIMER: The contents of this report are not to be used for advertising, publication, or promotional purposes. Citation of trade names does not constitute an official endorsement or approval of the use of such commercial products. All product names and trademarks cited are the property of their respective owners. The findings of this report are not to be construed as an official Department of the Army position unless so designated by other authorized documents. 


\section{Contents}

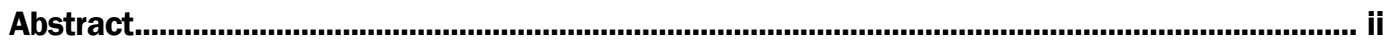

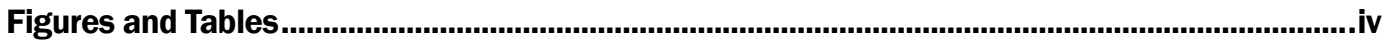

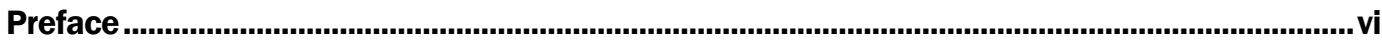

1 Introduction............................................................................................................................. 1

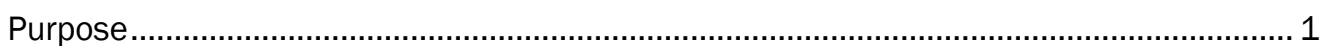

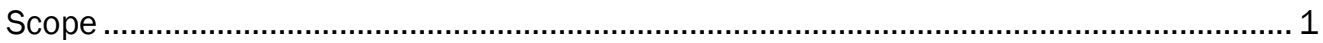

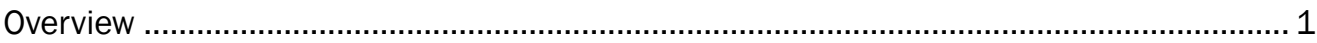

2 Logging In ................................................................................................................................. 2

3 Managing Content .............................................................................................................. 5

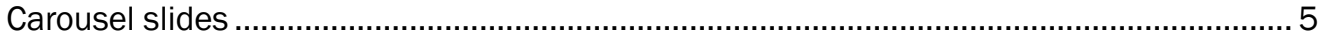

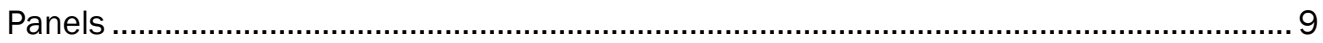

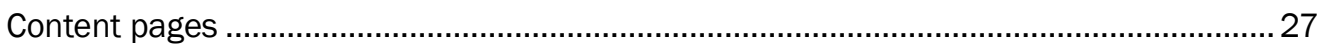

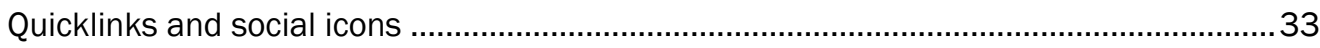

4 Conclusion.................................................................................................................................38

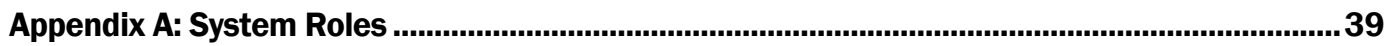

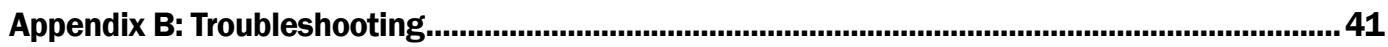

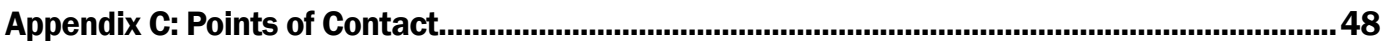

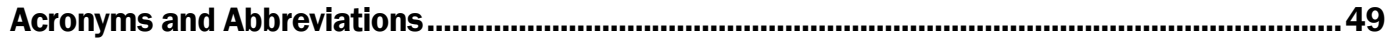

Report Documentation Page 


\section{Figures and Tables}

\section{Figures}

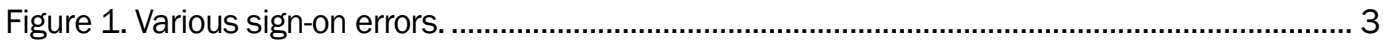

Figure 2. Standard DoD consent screen seen when visiting the site. ............................................. 3

Figure 3. CMS bar at the top right of the site. ……………..................................................... 4

Figure 4. Carousel slides section of the landing page ....................................................................... 5

Figure 5. Carousel slides section in the content editor.................................................................... 6

Figure 6. Carousel slide editor components................................................................................ 7

Figure 7. Carousel slide revisions........................................................................................ 9

Figure 8. Panels on the landing page................................................................................ 10

Figure 9. Panel with a video and link buttons. ............................................................................. 12

Figure 10. Internal link buttons with ERDC branding.................................................................. 12

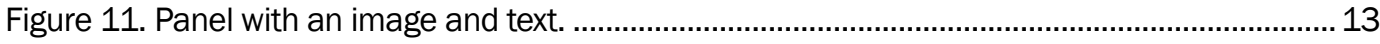

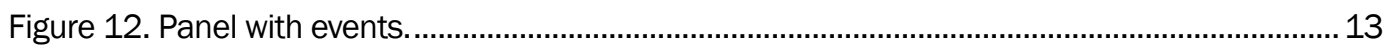

Figure 13. Panels in the content editor. ..................................................................................... 14

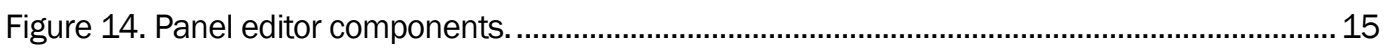

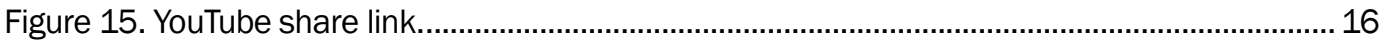

Figure 16. YouTube video link. ................................................................................................ 17

Figure 17. Livestream media library. ..................................................................................... 17

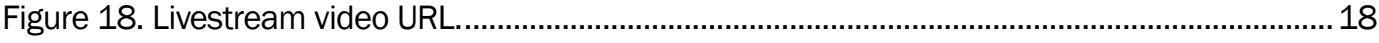

Figure 19. Wiki upload file link............................................................................................ 19

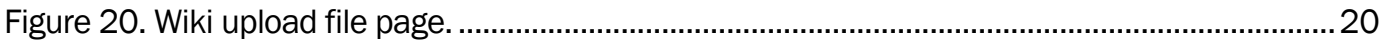

Figure 21. Wiki uploaded file list............................................................................................. 21

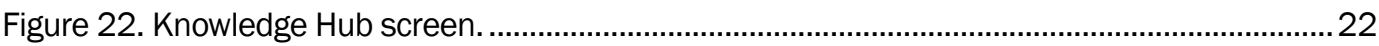

Figure 23. Knowledge Hub file upload.................................................................................... 23

Figure 24. Knowledge Hub copy video URL................................................................................. 23

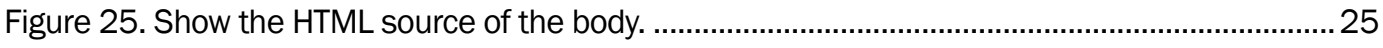

Figure 26. Picture and video embedding.............................................................................. 25

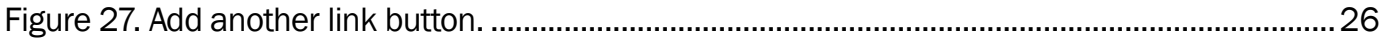

Figure 28. Adding a link to a content page ............................................................................... 28

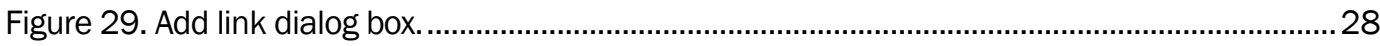

Figure 30. Completed page link............................................................................................. 29

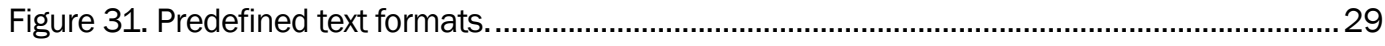

Figure 32. Page source code toggle ....................................................................................... 30

Figure 33. Insert image and video dialog boxes. ......................................................................... 30

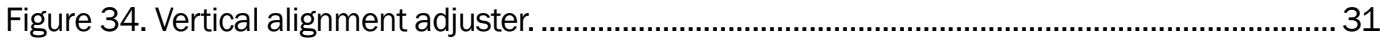

Figure 35. Horizontal alignment toolbar buttons. ....................................................................... 31

Figure 36. Add new content button. ...................................................................................................32 
Figure 37. Page editor taxonomy permissions.................................................................................. 33

Figure 38. Quicklinks section at the bottom of the landing page....................................................34

Figure 39. Quicklinks button................................................................................................. 34

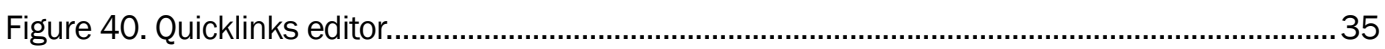

Figure 41. Quicklinks editor components. ..............................................................................

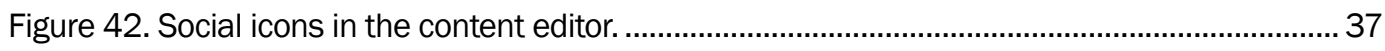

Figure 43. Social icon editor fields. ..................................................................................... 37

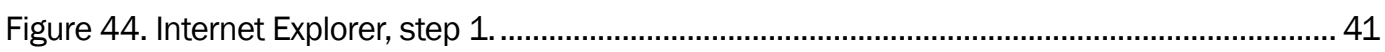

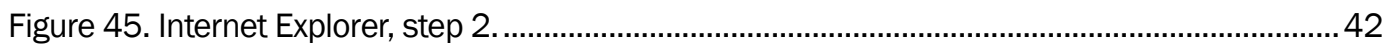

Figure 46. Internet Explorer, step 3 ..................................................................................... 42

Figure 47. Internet Explorer Developer Tools, step 1. ……….................................................... 43

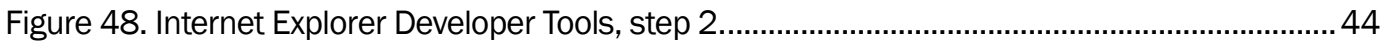

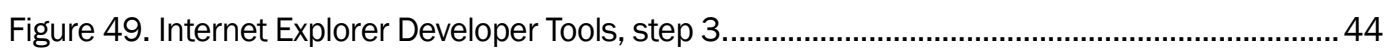

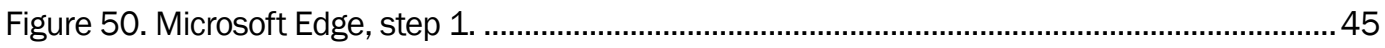

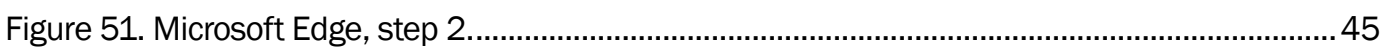

Figure 52. Google Chrome, step 1........................................................................................... 46

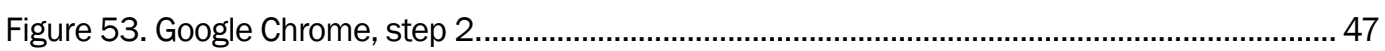

\section{Tables}

Table 1. System roles. 


\section{Preface}

This research was conducted for the ERDC Office of Research and Technology Transfer (ORTT) utilizing Future Innovation Funds (FIF) for, "ERDC Technology Transfer and Infusion/Knowledge Management," by the ERDC Information Technology Laboratory (ERDC-ITL). The technical monitor was Ms. Antisa C. Webb.

The work was performed by the Scientific Software Branch (SSB) of the Computational Science and Engineering Division (CSED), U.S. Army Engineer Research and Development Center - Information Technology Laboratory (ERDC-ITL). At the time of publication, Mr. Timothy W. Dunaway was Chief, SSB; and Dr. Jerrell R. Ballard, Jr. was Chief, CSED. The Deputy Director of ERDC-ITL was Ms. Patti S. Duett and the Director was Dr. David A. Horner.

COL Teresa A. Schlosser was the Commander of ERDC, and Dr. David W. Pittman was the Director. 


\section{Introduction}

\section{Purpose}

Knowledge management is an essential element to successfully executing research and development programs within the U.S. Army Engineer Research and Development Center (ERDC). Several iterations of knowledge management initiatives have been attempted over the years to address this vital role. From these initiatives, lessons were learned on the best ways to store and provide access to ERDC's vast knowledge base, which led to several knowledge management products being developed.

ERDC already has Wikis that store a tremendous amount of information for users inside and outside of ERDC to browse. In conjunction with the Discover ERDC landing page, these Wiki sites are the core of ERDC's knowledge storage. Each of these tools has a special role in ERDC's knowledge management initiatives, but combined into one central location, they provide a robust knowledge location and delivery service to ERDC employees and customers.

\section{Scope}

Maintaining the vast amount of content stored in these systems is the responsibility of Knowledge Management Representatives (KMRs). These content managers are assigned to various parts of the systems to create and maintain the knowledge within them. Although there are content management duties to be performed on all knowledge management systems across the ERDC, this document only details the processes required to maintain content on the Discover ERDC website.

\section{Overview}

Discover ERDC is built on top of a content management system (CMS) that allows various users with assigned roles to maintain the site's content. The CMS facilitates the editing of content without knowing how to edit files and write code. Within the CMS, KMRs are only shown content in the areas that have been assigned to them, which is done by a site administrator. The site administrator has the authority to assign and manage roles to authorized users. KMRs are assigned specific parts of the site that are their responsibility to maintain; they are only permitted to edit the content of these specific parts. 


\section{Logging In}

Discover ERDC utilizes ERDC's single sign on (SSO) system on the Research and Development Environment (RDE) network. Users that have been authenticated via SSO are automatically logged in to the CMS. Using SSO for authentication benefits users by allowing them to only log in once for any system that also uses SSO, so their CAC will not have to be used multiple times. SSO is used on Discover ERDC and the ERDC Wikis, so traversing between the two systems is seamless. Another added benefit for systems using SSO is the users are not required to remember user names or passwords since only a CAC and associated PIN are required.

Discover ERDC is housed on the external RDE network, but restricted to the .mil IP range. What that means to users is the site is accessible from both the U.S. Army Corps of Engineers-Information Technology (ACE-IT) and RDE networks. The site can be also be reached from all other DoD networks.

To log in to the site, first open a web browser and direct it to https://discover.erdc.dren.mil. Chrome, Safari, and Edge tend to work best, but Internet Explorer is also supported. A prompt will appear for the user to choose a certificate from their CAC. Make sure to always choose the EMAIL certificate. If the wrong certificate is selected, additional steps in will be needed to get back to a certificate prompt (Appendix B). Next, enter the CAC PIN when requested, which will bring up a consent screen (Figure 2).

Although rare, sign on errors can occur. If any of the error screens shown in Figure 1 appear, please review Appendix B for steps that solve the majority of these errors. 
Figure 1. Various sign-on errors.

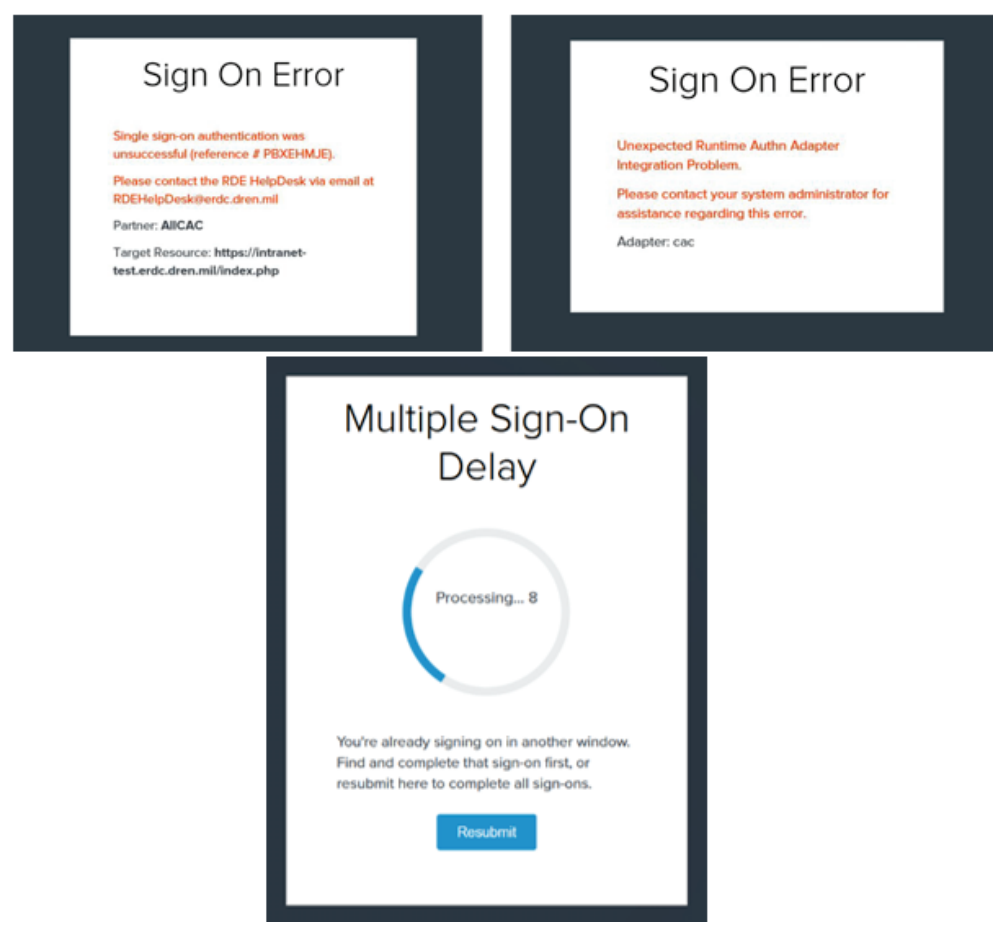

Once in, click the I Agree button, which will redirect the user to the Discover ERDC landing page.

Figure 2. Standard DoD consent screen seen when visiting the site.

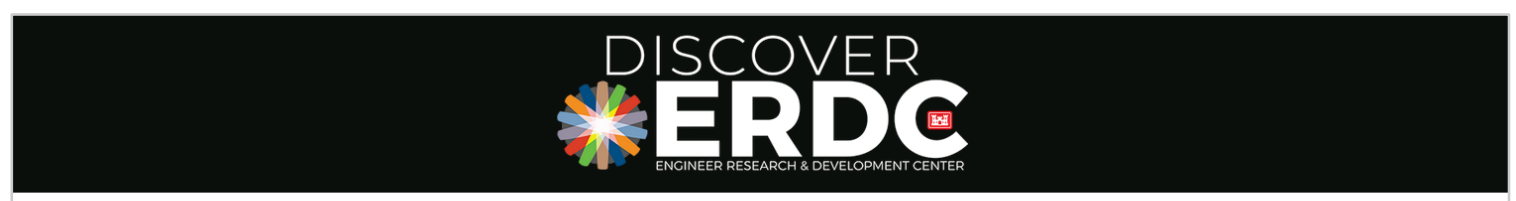

YOU ARE ACCESSING A U.S. GOVERNMENT (USG) INFORMATION SYSTEM (IS) THAT IS PROVIDED FOR USG-AUTHORIZED USE ONLY.

By using this IS (which includes any device attached to this IS), you consent to the following conditions:

- The USG routinely intercepts and monitors communications on this IS for purposes including, but not limited to, penetration testing, COMSEC monitoring, network operations and defense, personnel misconduct (PM), law enforcement (LE), and counterintelligence (Cl) investigations.

- At any time, the USG may inspect and seize data stored on this IS.

- Communications using, or data stored on, this IS are not private, are subject to routine monitoring, interception, and search, and may be disclosed or used for any USG-authorized purpose.

- This IS includes security measures (e.g., authentication and access controls) to protect USG interests.

- Notwithstanding the above, using this IS does not constitute consent to PM, LE or Cl investigative searching or monitoring of the content of privileged communications, or work product, related to personal representation or services by attorneys, psychotherapists, or clergy, and their assistants. Such communications and work product are private and confidential.

- Agreement to the Privacy Policy.

- Agreement to the Acceptable Use Policy.

\section{AGREE}


As mentioned previously, all KMRs have assigned content management roles, which are controlled by a CMS bar that will appear at the top of the page after successful log in. Depending on their assigned roles, this bar may vary in appearance, but the bar will always be shown (Figure 3).

Figure 3. CMS bar at the top right of the site.

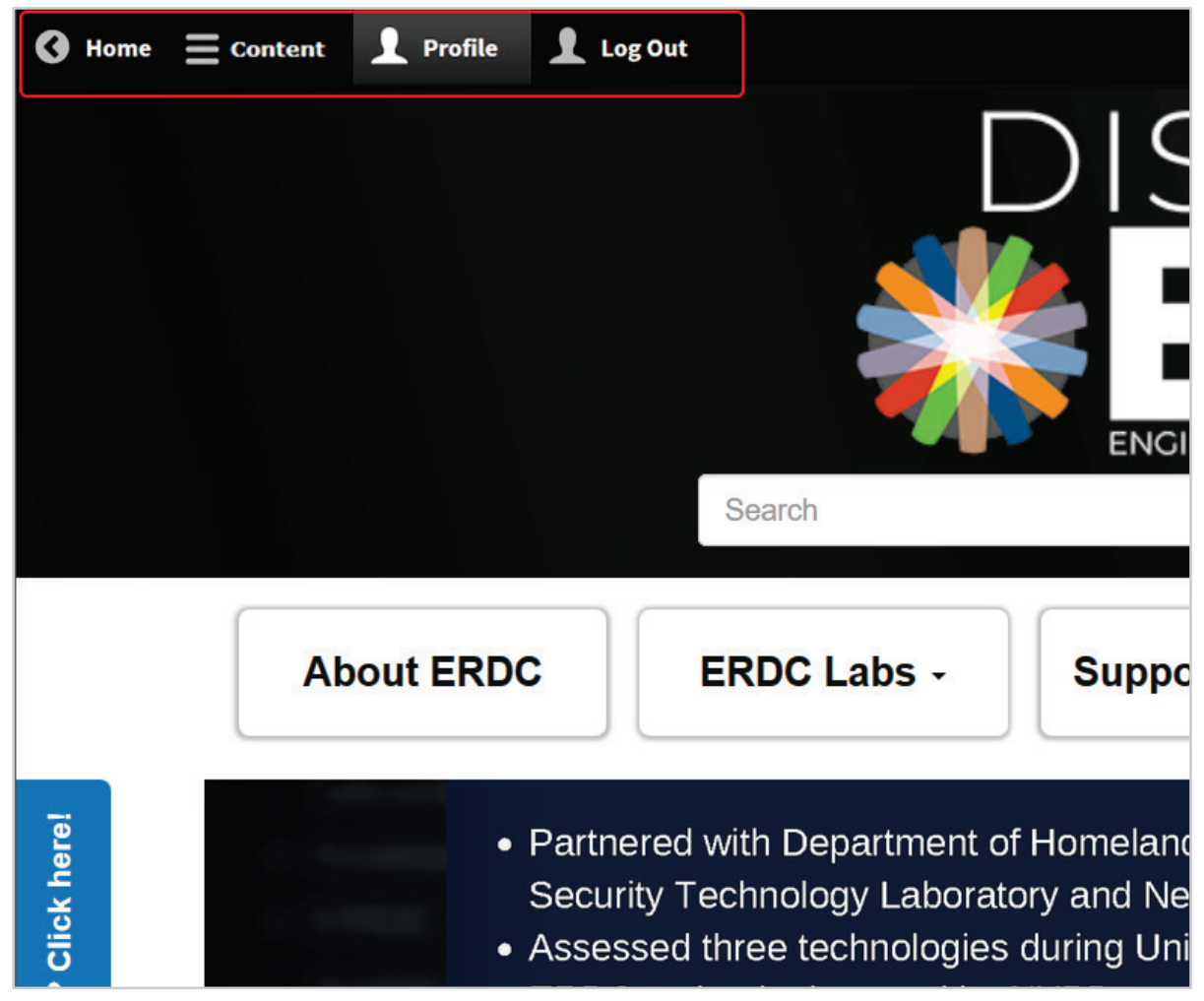




\section{Managing Content}

There are several parts and pieces that make up the Discover ERDC website, which are used to house and display content. Each KMR is assigned a role (or multiple roles) and they are responsible for creating and maintaining the content specified by those assigned roles. Each role corresponds to an individual piece of the Discover ERDC website. The list of editable content areas on the site includes:

- Carousel Slides

- Panels

- Content Pages

- Social Icons

The Content button in the CMS bar is used to access the content the KMR is responsible for maintaining.

\section{Carousel slides}

The carousel is the rotating image section at the top of the page (Figure 4). It contains three editable images (slides), and each of these images contain two text labels: Header and Description. Each carousel image is also a hyperlink that leads to content related to the image.

Figure 4. Carousel slides section of the landing page.

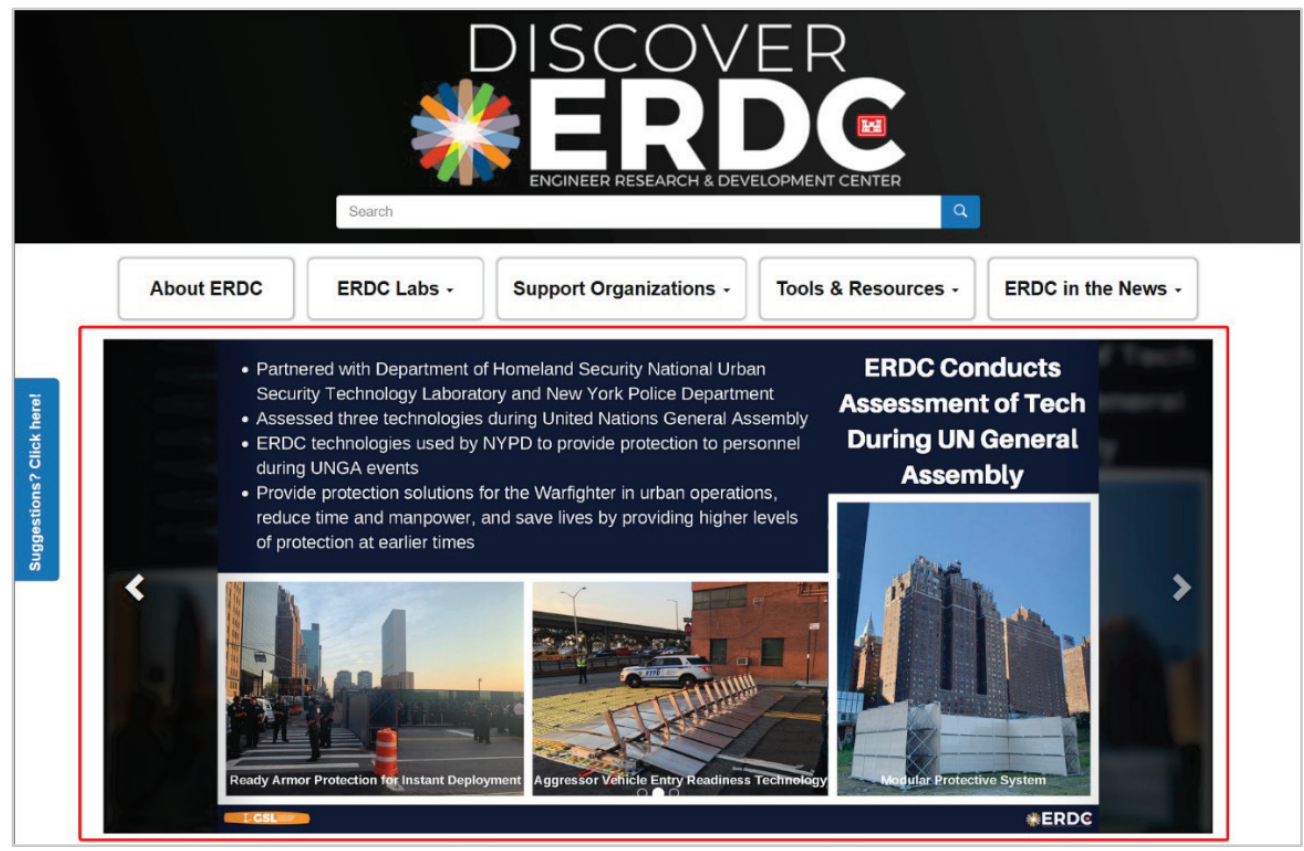


Carousel slides can only be edited by KMRs with the assigned role. Those KMRs will see a Carousel Slides section in their content management area (Figure 5). Every KMR's screen will look a little different depending on their authorization level and roles.

Figure 5. Carousel slides section in the content editor.

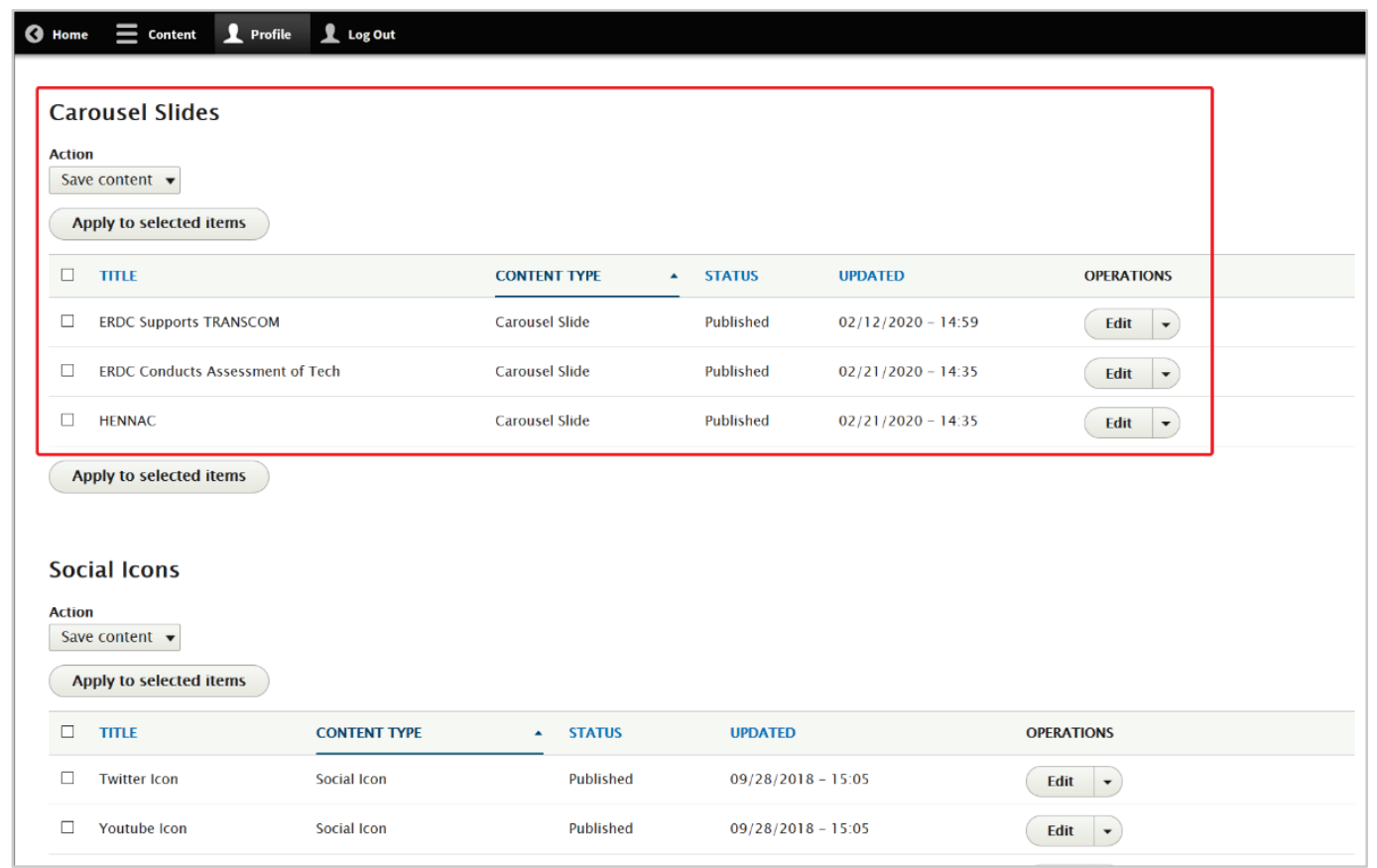

To edit a carousel slide, click the Edit button in the Operations column. This brings up the Edit Carousel Slide window and opens the Edit tab (Figure 6). 
Figure 6. Carousel slide editor components.

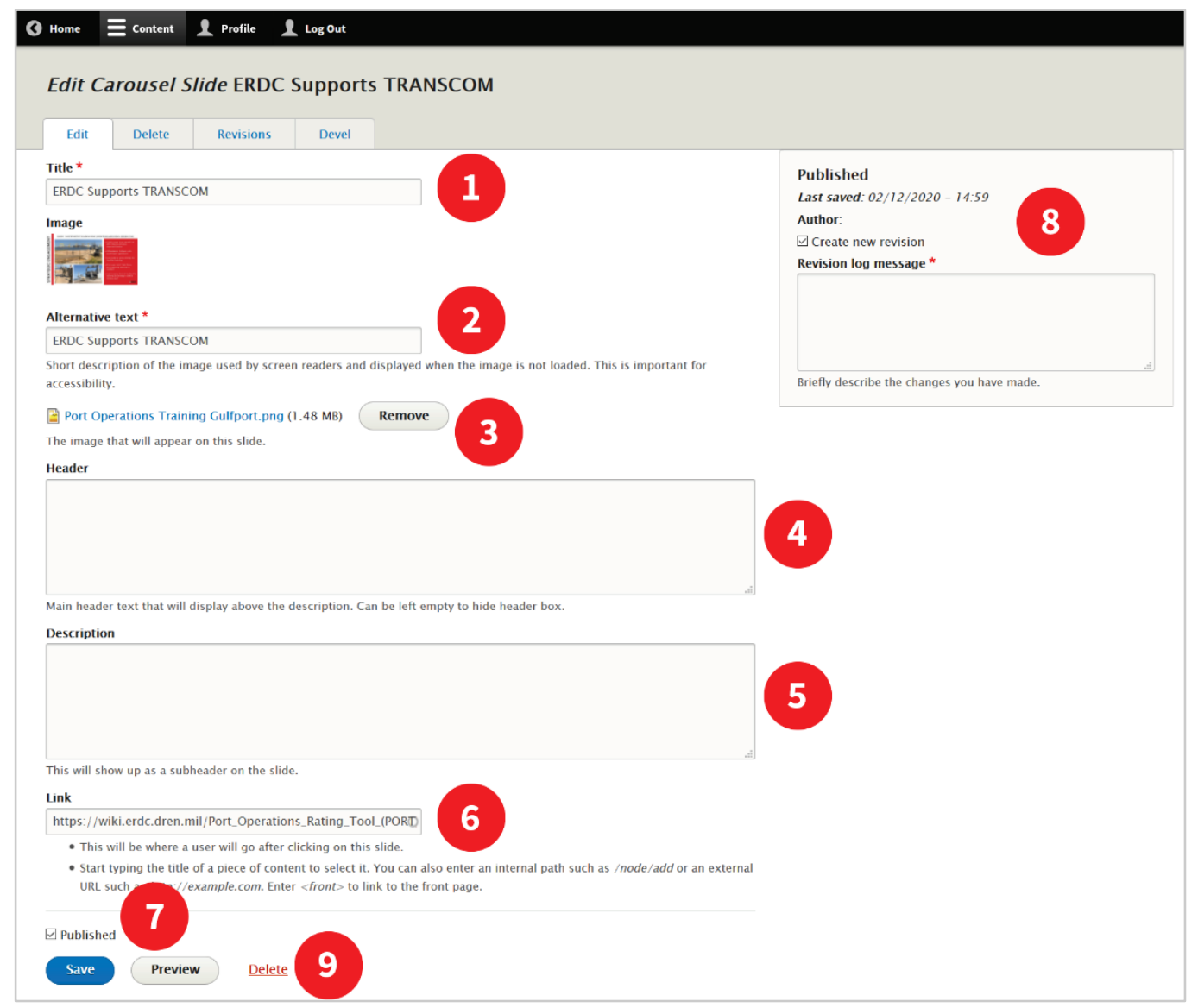

The following fields are available to edit and are numbered in Figure 6:

1. Title - This text is used to distinguish slides from one another. It does not appear on the actual slide, but it is there for the KMRs benefit. Recall the list of slides in the CMS and the title appears in the first column. Title is a required field.

2. Image - This is the image file that will be shown on the slide. If an image has already been assigned, a small thumbnail will be shown of the image and a Remove button will appear. The current image must be removed prior to adding a new one. Choose a file from your computer using the Choose File button. But, be careful, once the Remove button is clicked, the image is removed and cannot be retrieved after saved. The image file type must be png, gif, jpg, or jpeg. The carousel is $1120 \times 500$ pixels, which is a wide screen format. If an image is uploaded that is not that wide, the system will automatically fill the gaps on each side. A thumbnail preview of the new file will appear after a file is chosen. The file will be uploaded to the site when after the changes are saved and published. This is a required field. 
3. Alternative text - This text will be used by screen readers, search engines, or displayed in place of the image when it cannot be loaded. Enter a brief description of the image. This is a required field.

4. Header - This is the text that appears as an overlay in the first (larger font size) text label, near the bottom right of each carousel image. Treat this text as a headline for the image. Simply leave it blank if a header label is not needed on the image.

5. Description - This is the text that appears as an overlay in the second (smaller font size) text label, below the title of each carousel image. Treat this as a one sentence description of the image. Simply leave it blank if a description label is not needed on the image.

6. Link - This the URL, or hyperlink, assigned to the image. When a user clicks the image, the URL directs them where you want them to go. This can be a link to other internal content, or it can be a link to anywhere on the internet. The Link box is content aware, so when you start typing the title of an internal page for example, it will auto populate. Be careful to include the http:// (or https://) in front of the link when linking to external content.

7. Published - Check this box to show the slide in the carousel. If it does not need to be shown on the carousel, uncheck the box.

8. Published Message - The CMS has a feature that allows content to be restored back to a previous state. These states are saved as "revisions." Every time a content type is edited, there is an opportunity to save it as a revision. Creating a revision allows temporary changes to the slide, then at a later date, it can revert back to a previous state without having to make further changes. The last saved date (if there is one) and the last author (if there is one) will be shown here. The checkbox next to Create new revision is checked by default, and it should normally stay checked. But, if for some reason a revision does not need to be saved, uncheck the box. Regardless of the checkbox status, a log message is required. This helps others know what was done when the content was edited. Make sure to provide a good description of what was changed. That way, determining which revision is needed later will be easier.

9. Action Buttons - Use the Save button to save changes, Preview to see how the changes will look before saving, and Delete to completely delete the content. It is recommended to use the preview before publishing changes the slide can be seen in its final state before publishing it to the live site. That way, if something does not look quite right, it can changed before it goes live. Clicking the Save button immediately publishes the 
changes to the live site when the Published box is checked, so make sure to preview first.

There is another tab on the Edit Carousel Slide window labeled Revisions (Figure 7). Recall the revision check box. Those saved revisions will be shown on this tab and the Revert button can be used to revert back to the state of the slide at the time the revision was created. Switching between revisions can be done as many times as needed.

Figure 7. Carousel slide revisions.

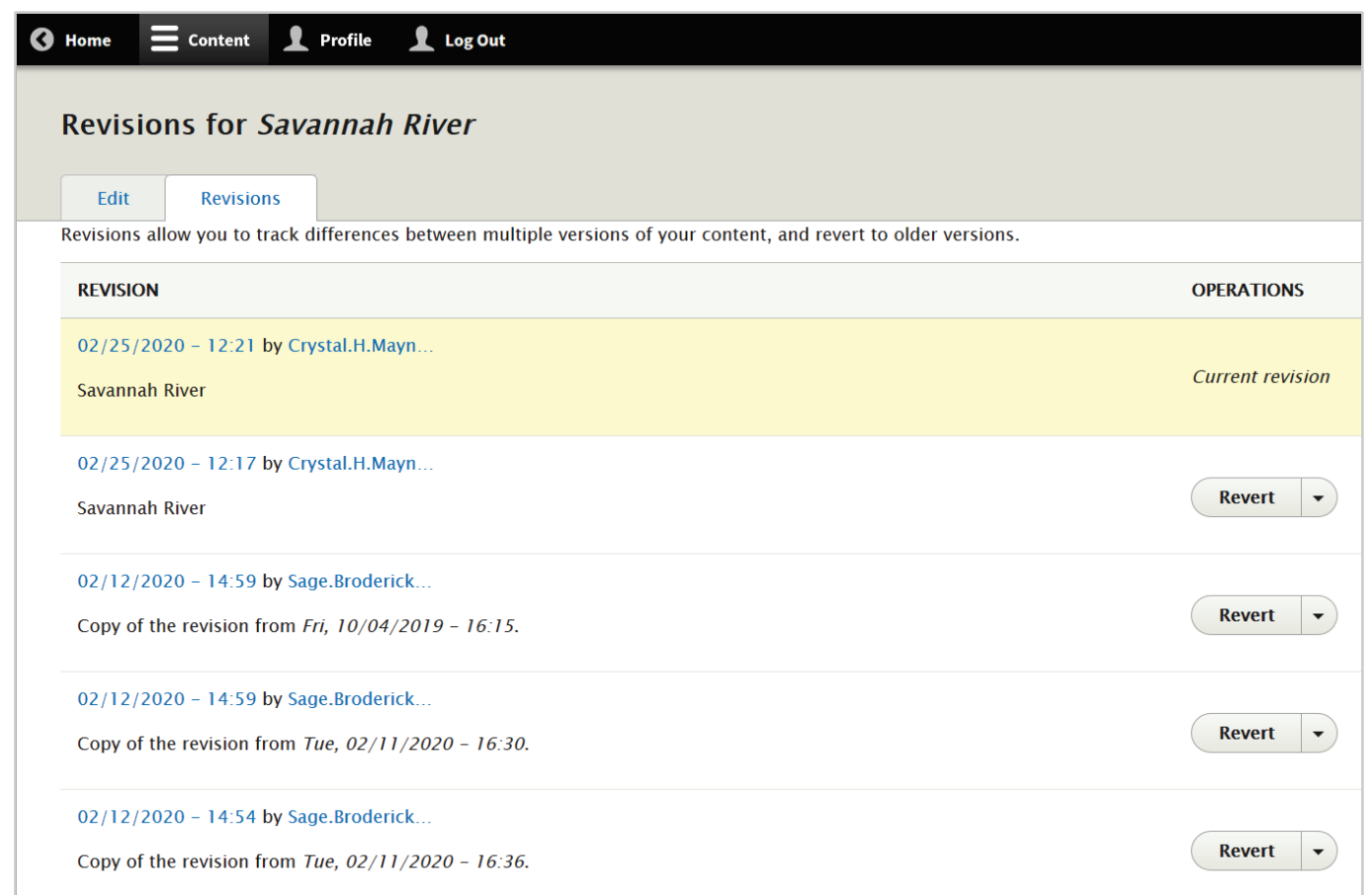

\section{Panels}

There are fifteen panels on the landing page, each representing a unique content area. These panels can be seen in Figure 8 . 
Figure 8. Panels on the landing page.
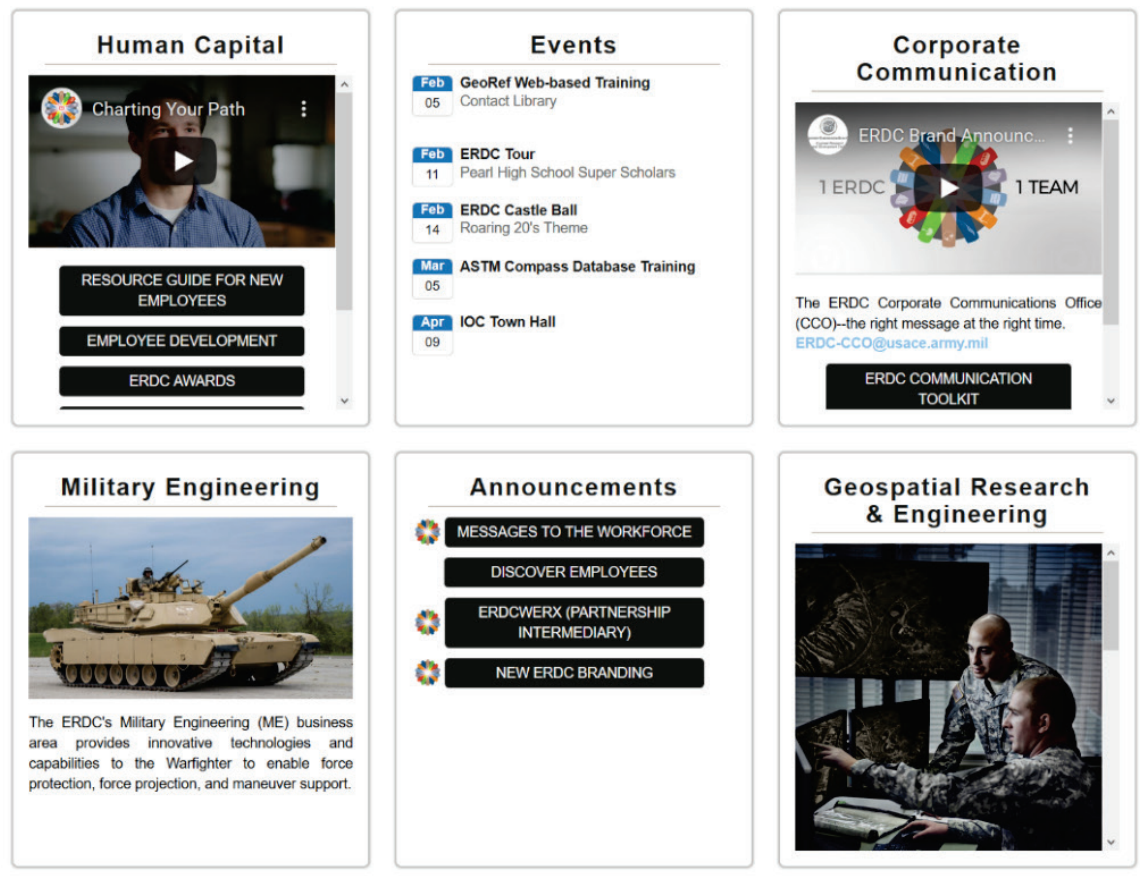

Civil Works: Flood \&
Coastal
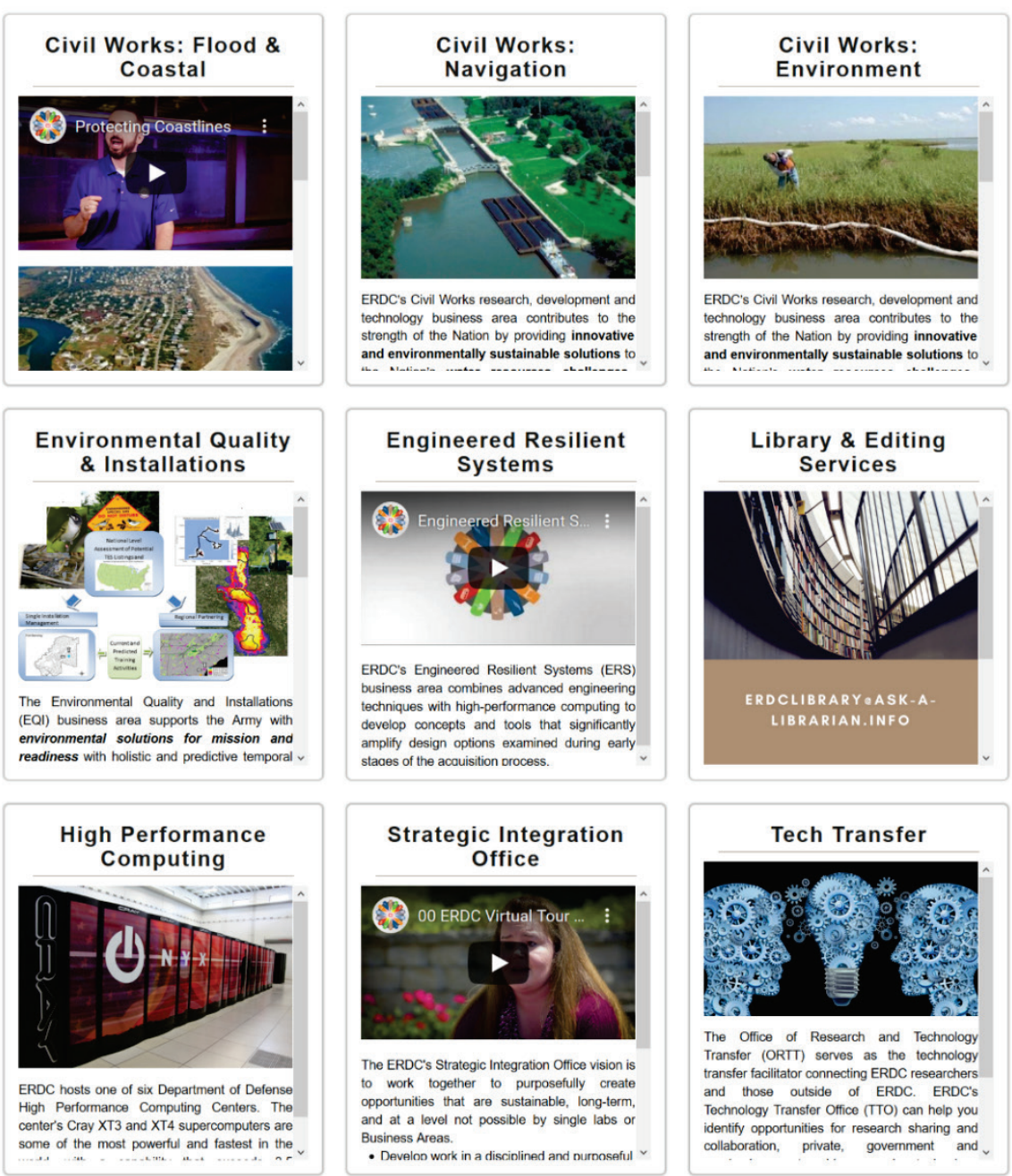

Strategic Integration Office

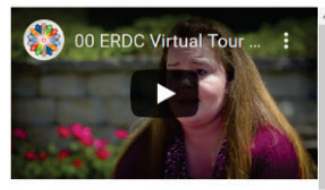

The ERDC"s Strategic Integration Office vision is to work together to purposefully create opportunities that are sustainable, long-term, and at a level not possible by single labs or Business Areas.

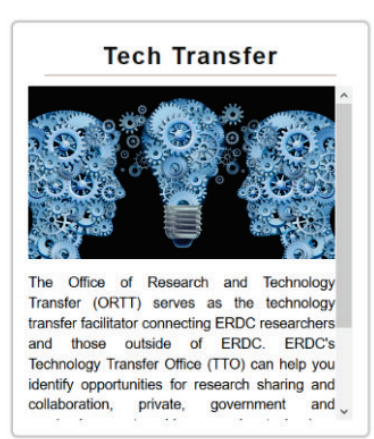


The panels are categorized as follows:

- Human capital

- Events

- Corporate Communication

- Military Engineering

- Announcements

- Geospatial Research \& Engineering

- Civil Works: Flood \& Coastal

- Civil Works: Navigation

- Civil Works: Environment

- Environmental Quality and Installations

- Engineered Resilient Systems

- Library \& Editing Services

- High Performance Computing

- Strategic Integration Office

- Tech Transfer

These panels appear in the center of the landing page as 3 columns of boxes. Currently, the way the system is set up, all panels are the same height, and they will scroll when the content exceeds the defined height. This provides a bit of uniformity. Each panel has a title that is linkable, and content beneath. Panels can contain all sorts of content; text, pictures, videos, events, etc.

The panel in Figure 9 contains an embedded video and link buttons. Content types can be combined on a single panel, so it is not restricted to a single type. All content is automatically formatted to fit inside the panel width-wise. Videos can derive from a variety of sources like YouTube, ERDC Livestream, etc. Embedding videos will be discussed in more detail later in the report. 
Figure 9. Panel with a video and link buttons.

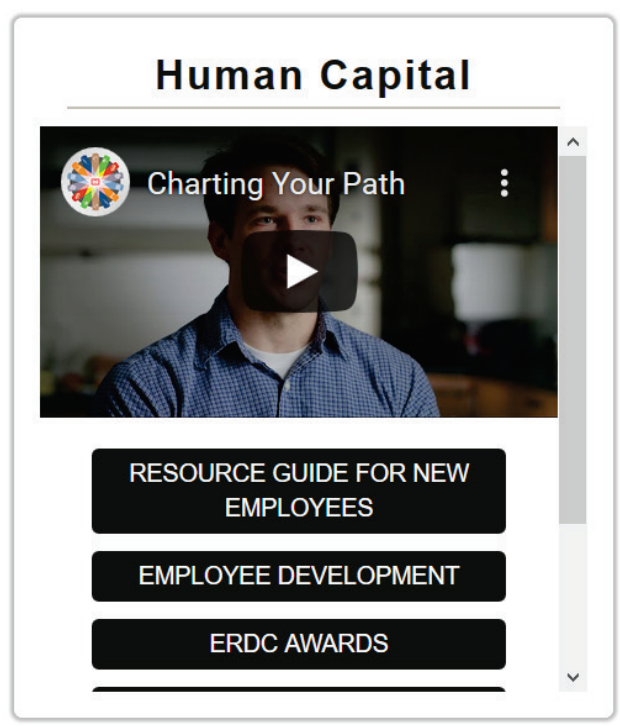

Link buttons function just like a normal internet link, but they are styled to look like buttons. These are typically used when a list of links should be displayed. Some link buttons direct users to content only available inside ERDC networks, so they would need to be marked as such with ERDC branding (Figure 10).

Figure 10. Internal link buttons with ERDC branding.

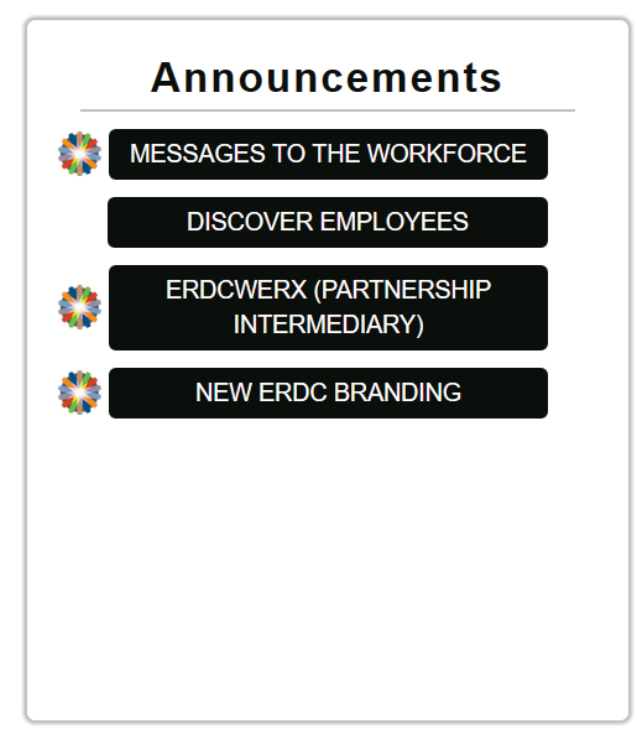

Figure 11 shows a panel with a simple image and text. 
Figure 11. Panel with an image and text.

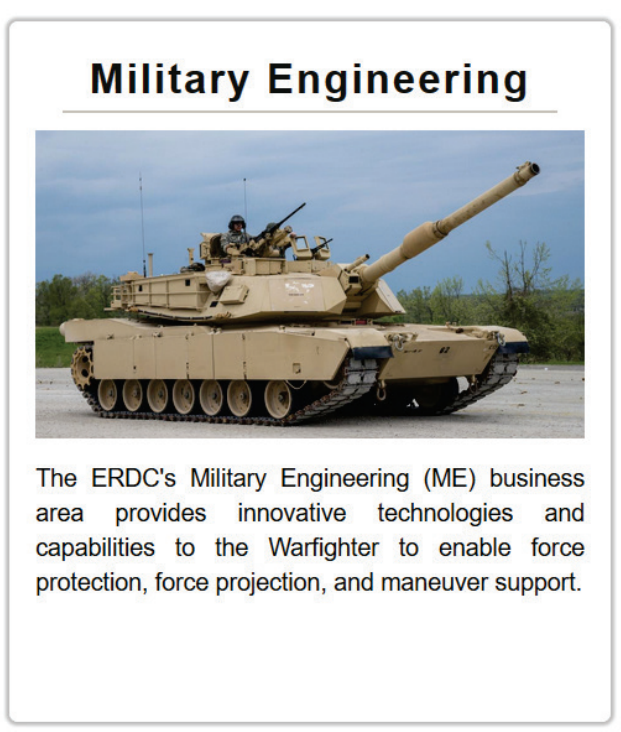

Figure 12 shows a panel containing events.

Figure 12. Panel with events.

\begin{tabular}{|c|c|}
\hline & \multicolumn{1}{c|}{ EVents } \\
\hline Feb & $\begin{array}{l}\text { GeoRef Web-based Training } \\
\text { Contact Library }\end{array}$ \\
\hline 05 & \\
\hline Feb & ERDC Tour \\
\hline 11 & Pearl High School Super Scholars \\
\hline Feb & ERDC Castle Ball \\
\hline 14 & Roaring 20's Theme \\
\hline Mar & ASTM Compass Database Training \\
\hline 05 & \\
\hline Apr & \\
\hline 09 & \\
\hline
\end{tabular}

Panels are also allowed to have bulleted and numbered lists. Any HTML can be added to a panel.

Not all roles are assigned a panel to maintain. If assigned a panel maintenance role, the panel will appear in the CMS. The assigned panels will be labeled Panel under the Content Type column (Figure 13). 
Figure 13. Panels in the content editor.

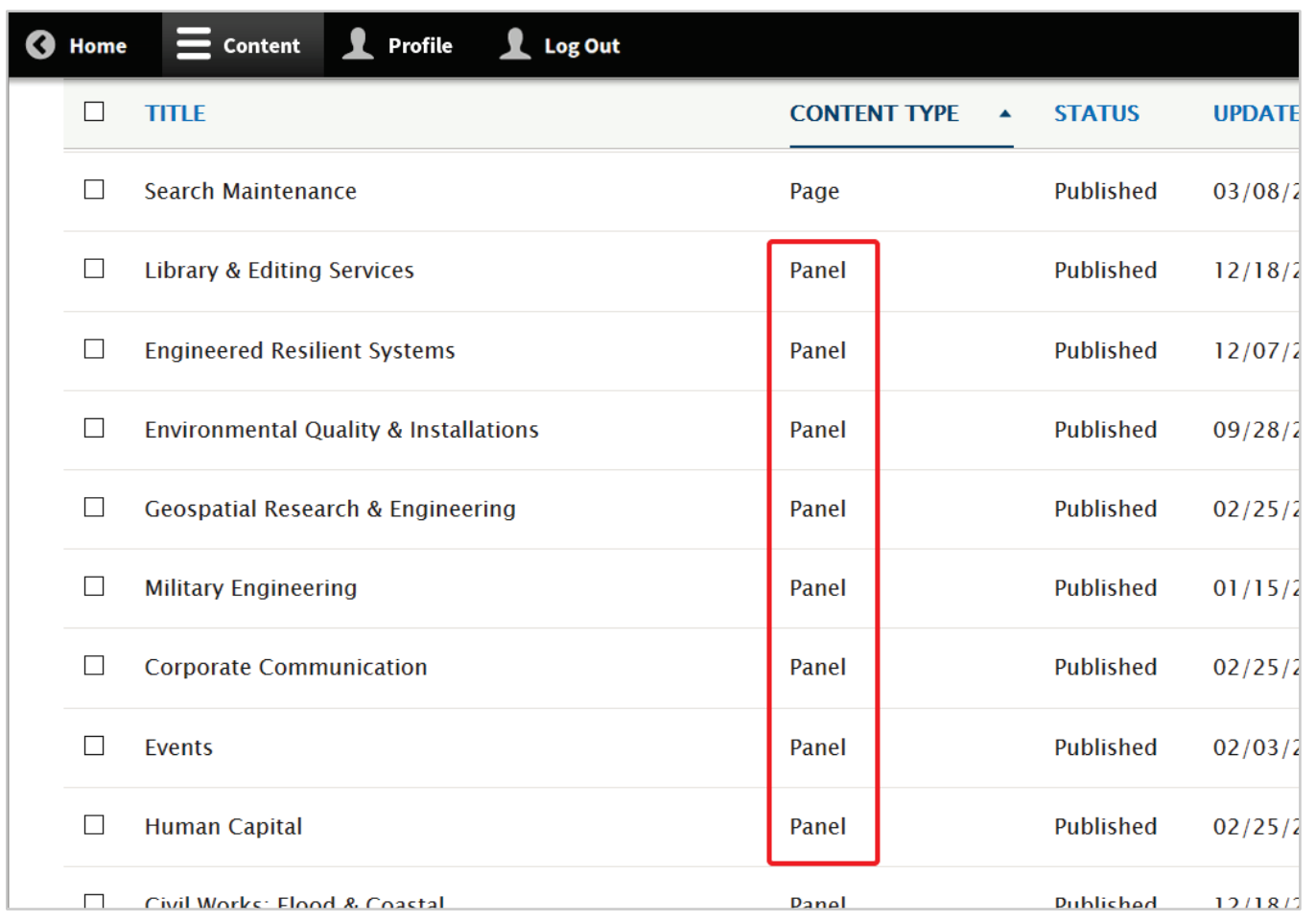

To edit a panel, click the Edit button in the Operations column. This brings up the Edit Panel window and opens the Edit tab, which can be seen in Figure 14. 
Figure 14. Panel editor components.

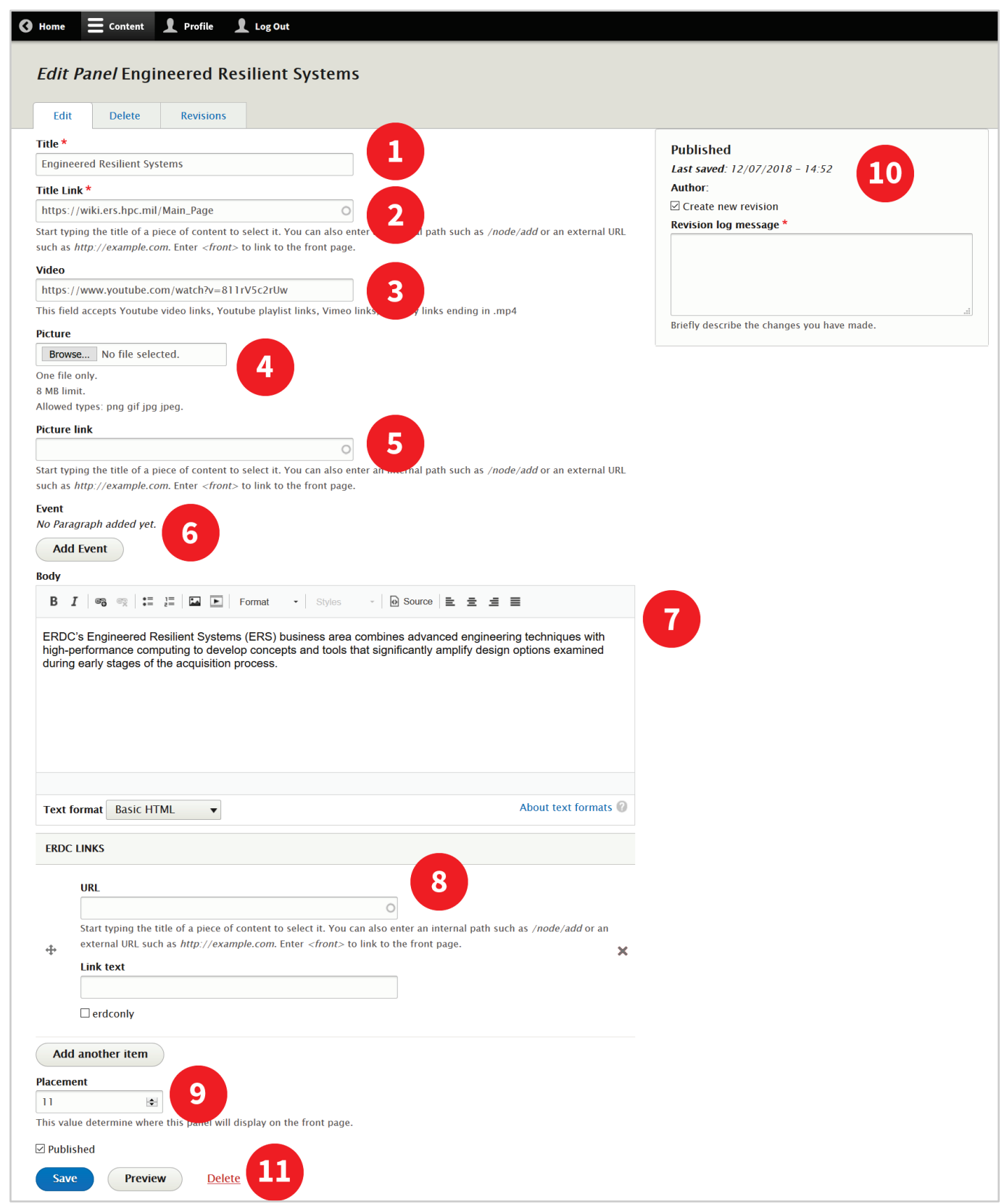

The following fields are available to edit and are numbered in Figure 14:

1. Title - This text is found at the top of the panel with a horizontal line underneath. Treat this text as a headline for the panel. This is a required field for every panel.

2. Title Link - This is the URL the title will link to. This is very similar to the Link field seen earlier when editing Carousel Slides. When a user clicks the panel's Title, the URL is where you want them to go. This can be a 
link to other internal content, or it can be a link to anywhere on the internet. The Title Link box is content aware, so when typing the title of an internal page for example, it will auto populate. Be careful when linking to external content to include the http:// (or https://) in front of the link. This is a required field.

3. Video - This is where videos can be embedded on a panel. Embedded videos play directly from the auto-sized player instead of having to upload them to the site. Videos can derive from a variety of sources; YouTube and Livestream just to name a couple. To embed a video, the video's .MP4 file must be located. MP4 is a video file format standard that is used all across the internet. When embedding a YouTube video, the URL for the MP4 file is easy to locate; all that has to be done is clicking the Share link below the video to the right (Figure 15).

Figure 15. YouTube share link.

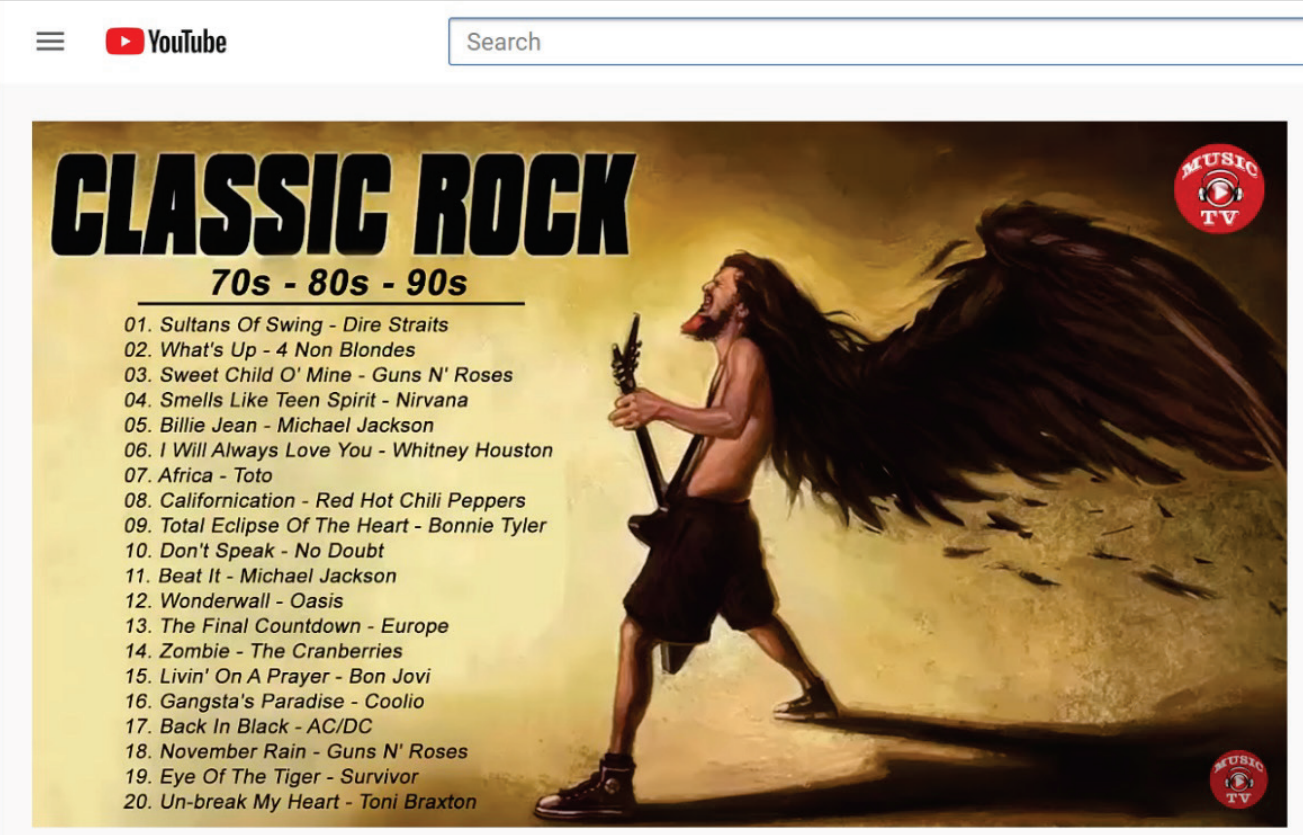

Top 100 Best Classic Rock Songs of All Time - Greatest Classic Rock Songs Playlist 70s 80s 90s 33,533 views $\cdot$ Jul 17, 2019 209 I 2094 SHARE

To embed a YouTube video, copy the link shown and paste it into the Video box in the panel editor (Figure 16). ERDC has a YouTube channel, but it is limited to public release content only. 
Figure 16. YouTube video link.

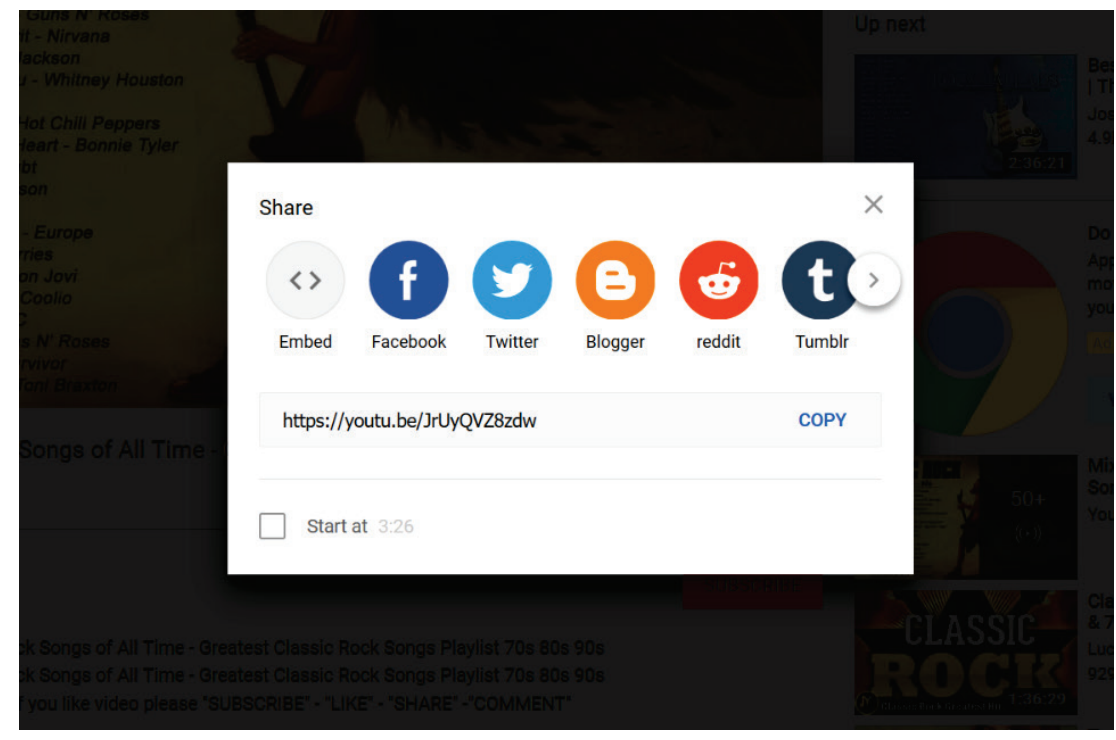

There are other methods of hosting ERDC videos inside the ERDC network. One new and exciting system is ERDC Livestream. It's a YouTube-like service for internal video live streaming and hosting. Each laboratory has their own "channel" where videos can be uploaded, tagged, and played directly from the Livestream website located at https://livestream.erdc.dren.mil. At the time of this writing, a separate user account is required to upload videos to the Livestream system and viewing MP4 URLs. There is not a formal process for this, but contacting the RDE helpdesk is the best way to request an account. Once you have an account and log in to the admin area, click on Media then Library from menu on the left-hand side (Figure 17).

Figure 17. Livestream media library.

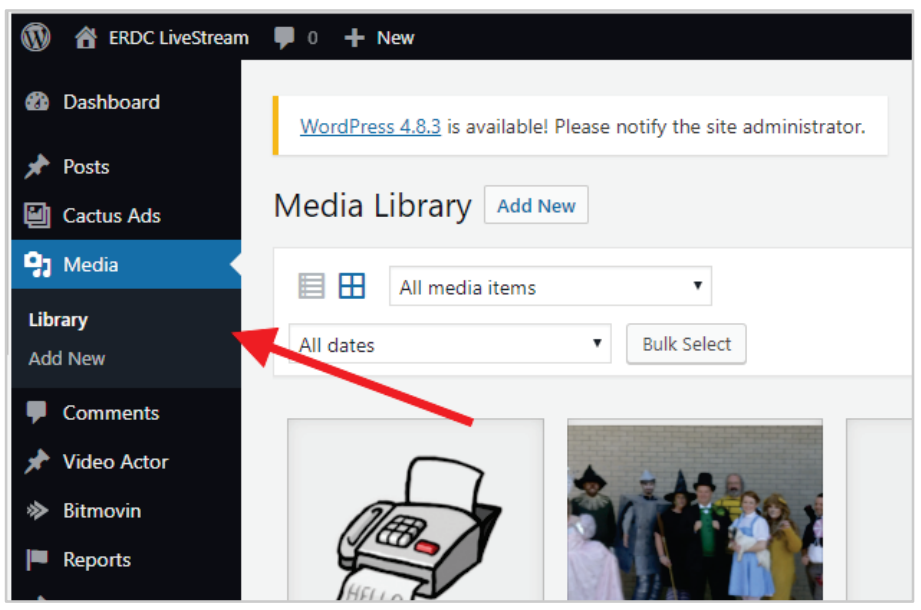


Next, locate the video that needs to be embedded and click on it. There are search and sorting functions near the top to help locate the video. After clicking the video, the URL box can be seen (Figure 18).

Figure 18. Livestream video URL.

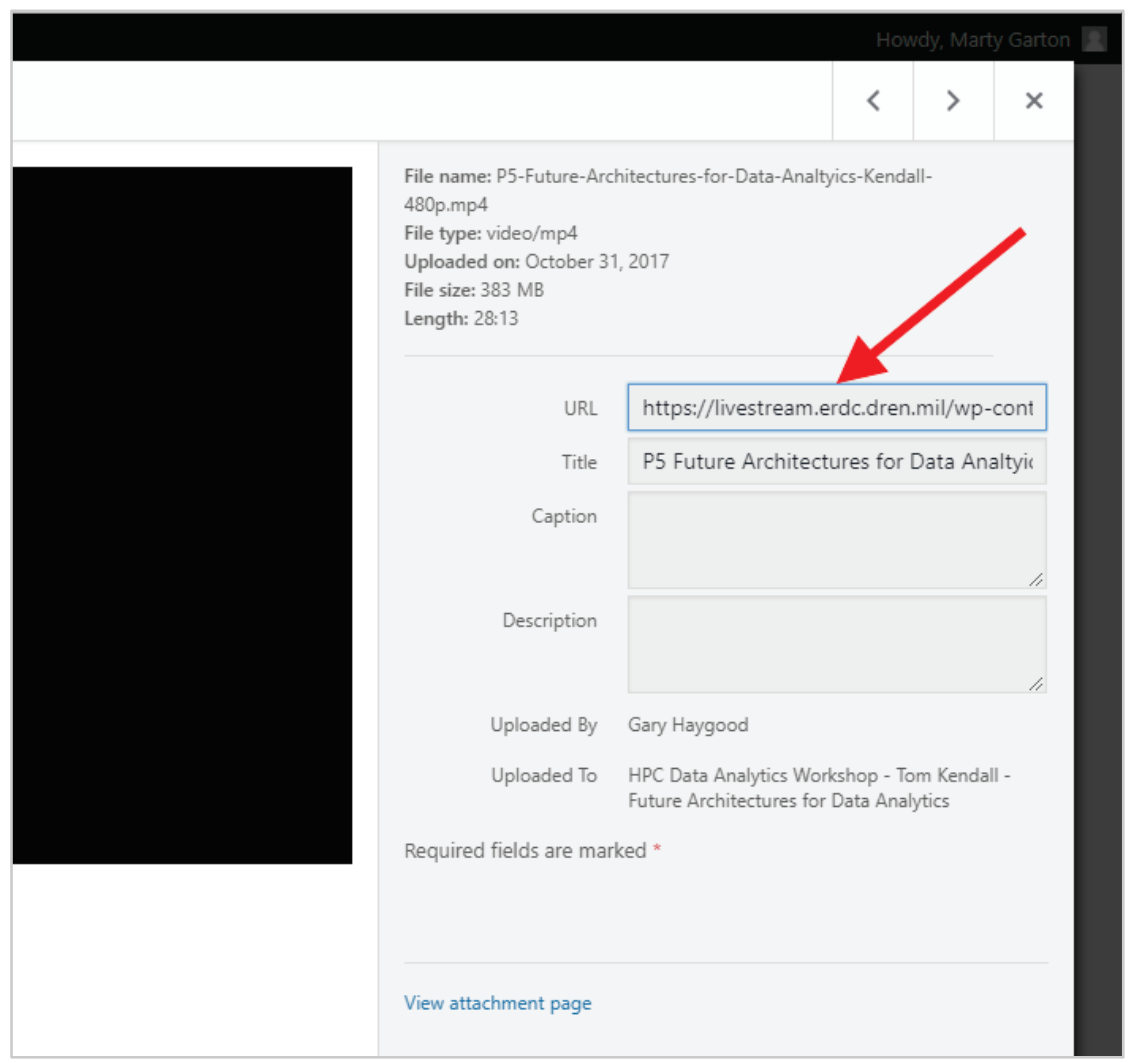

To embed a Livestream video onto the panel, copy the entire URL and paste it into the Video box.

Another option for video hosting is the ERDCpedia Wiki pages. All projects executed by ERDC have individual Wiki pages, and tons of other content is collected there as well. As of FY18, media, such as videos and pictures, can now be hosted inside the Wiki system. Start by accessing the ERDC Pedia site located at https://wiki.erdc.dren.mil or the Inside ERDC Wiki at https://insideerdc.erdc.dren.mil. The Wikis are connected to SSO, so the user should not have to re-authenticate with their CAC if coming from the Discover ERDC site. To upload a video, use the Upload file link in the left-hand side menu as seen in Figure 19. 
Figure 19. Wiki upload file link.

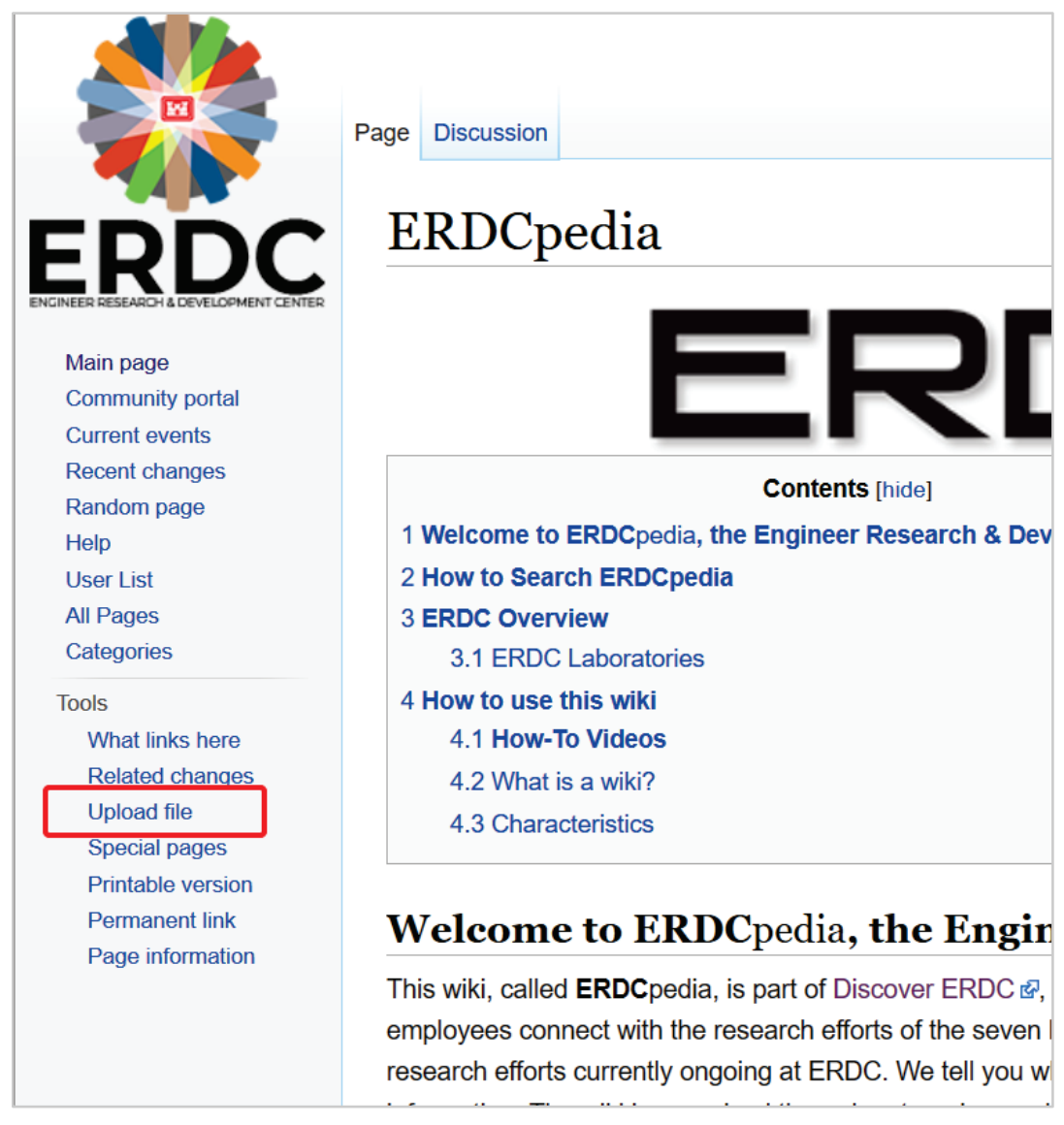

This will lead to the file upload form. Fill in each field on the form by choosing the file, giving it a file name, and a summary, then click the Upload file button (Figure 20). 
Figure 20. Wiki upload file page.

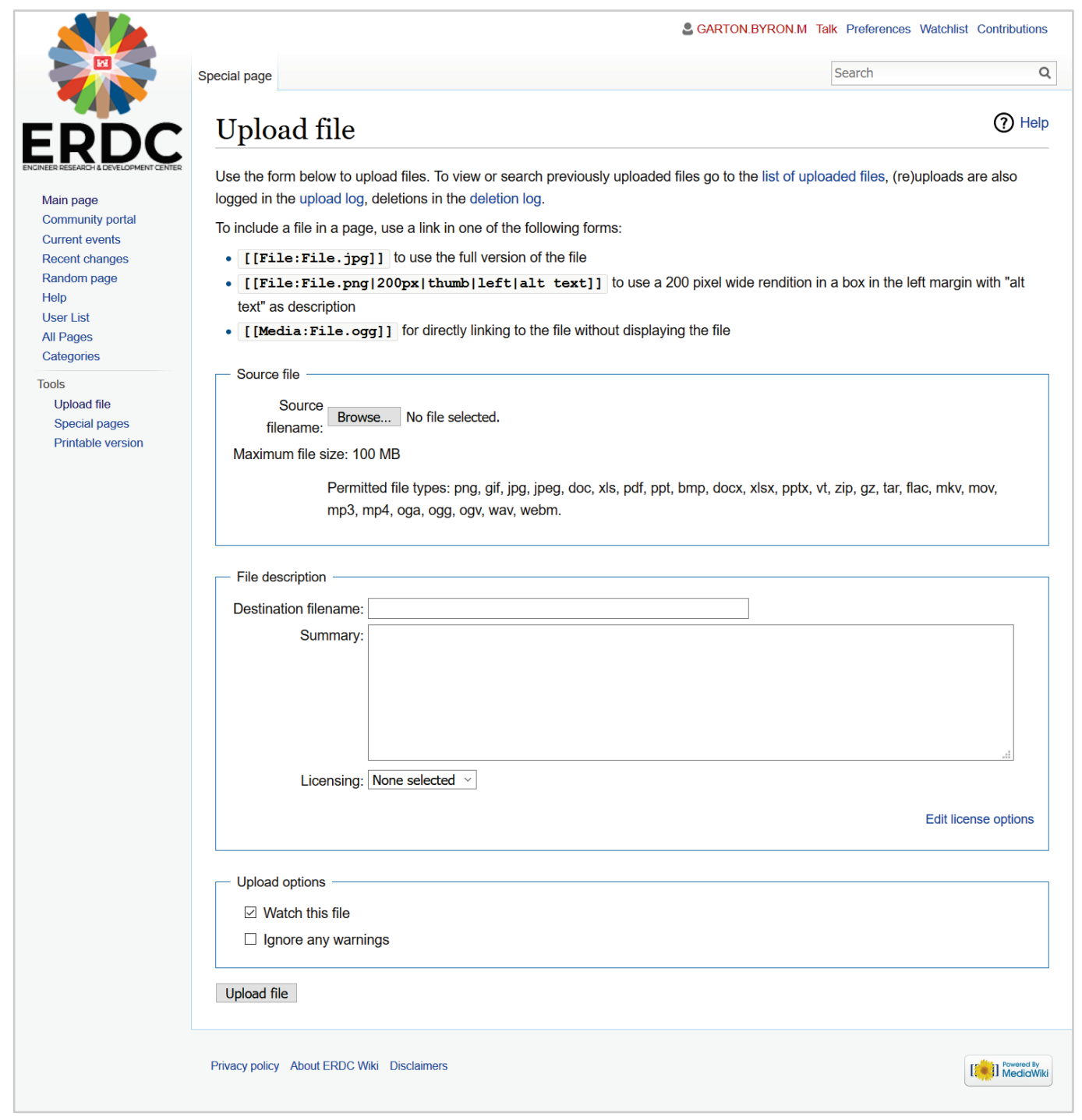

Complete all required fields, then once the file is uploaded, go back to the Upload file page and click the list of uploaded files link near the top. This will lead to a table that lists all files that users have uploaded (Figure 21). Use the search box and table sorting features to locate the video file that was uploaded. Once the correct file has been found, right click the link in the Name column and choose Copy link address. This wording may be slightly different in various browsers, but it should be very similar. 
Figure 21. Wiki uploaded file list.

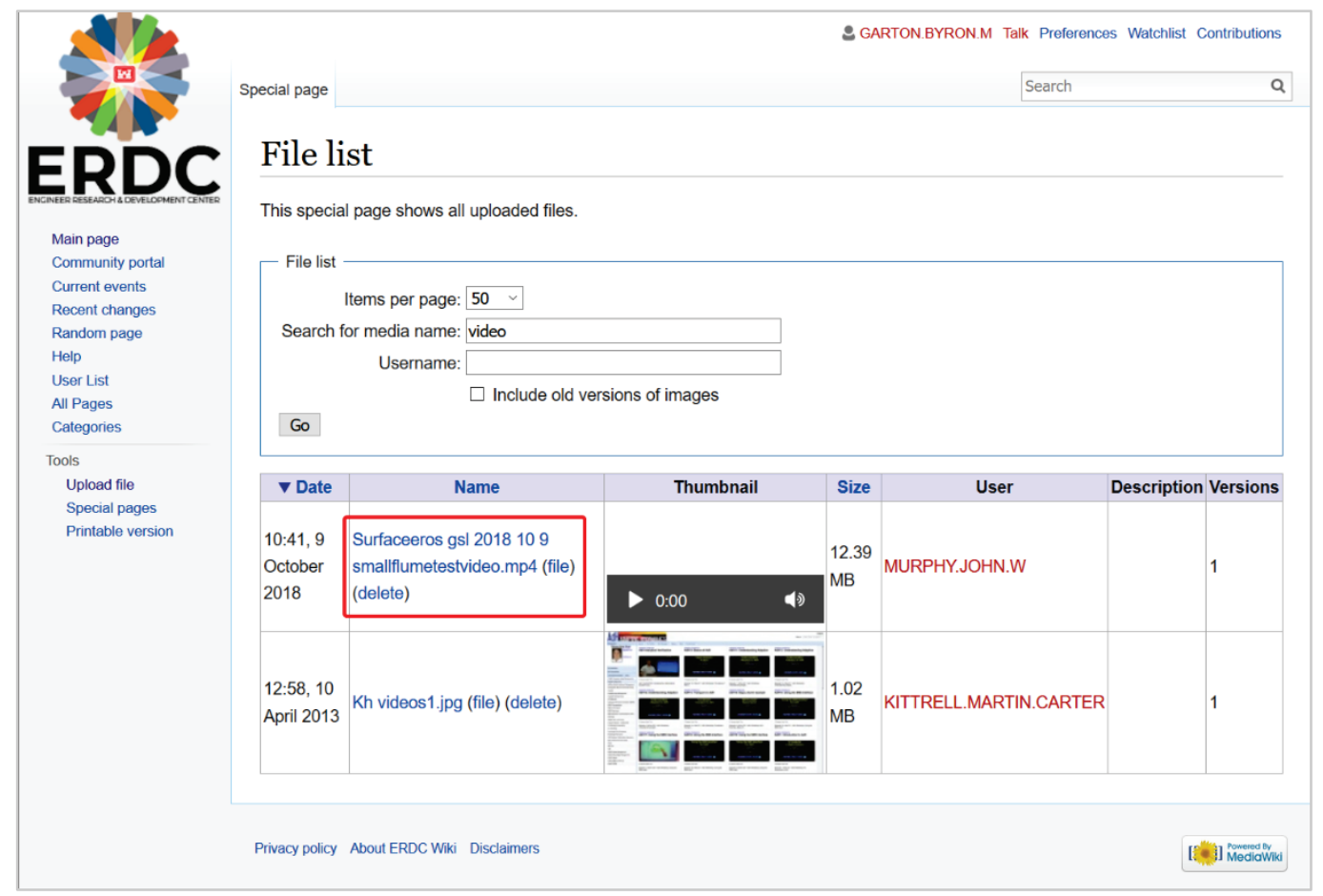

To embed a Wiki video onto a panel, paste the video's MP4 URL into the Video box on Discover ERDC the same way as before.

One final option for video hosting is the ERDC Knowledge Hub site. Knowledge Hub allows users to upload media content like videos similar to Livestream. Knowledge Hub is located at https://knowledge.erdc.dren.mil and requires a CAC to access. This system is not SSO enabled, so the CAC will be needed again if going there from Discover ERDC. Once there, the user will be directed to their profile page with recent events shown on the Events tab. As shown in Figure 22, the two tabs needed for this tasks are File Manager and Videos. 
Figure 22. Knowledge Hub screen.

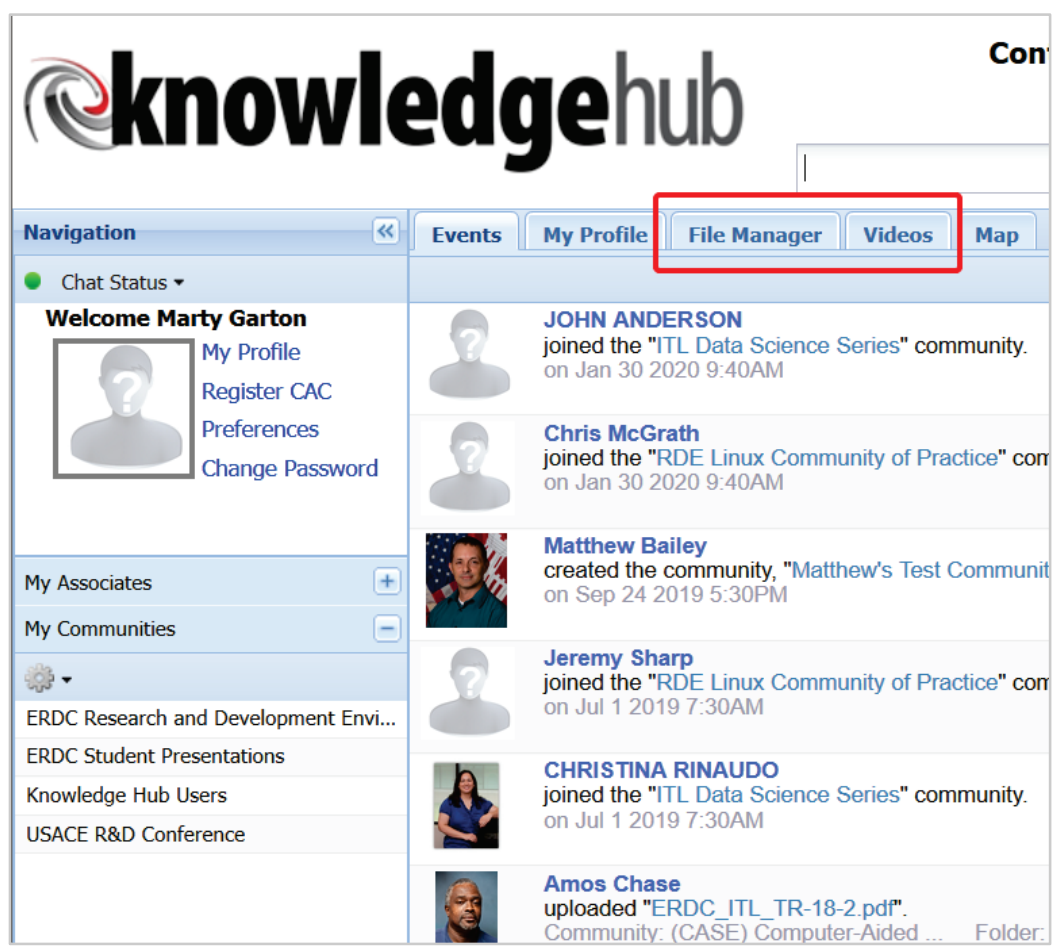

The File Manager tab is used to upload files to your Knowledge Hub account. On that tab, folders can be seen that are accessible to the user. This includes folders associated with communities joined and a My Documents folder that every Knowledge Hub user has. Using the My Documents folder for hosting videos is recommended, unless there is a specific community folder that needs to be used. Use the Upload button to copy a local video file to your Knowledge Hub account (Figure 23). 
Figure 23. Knowledge Hub file upload.

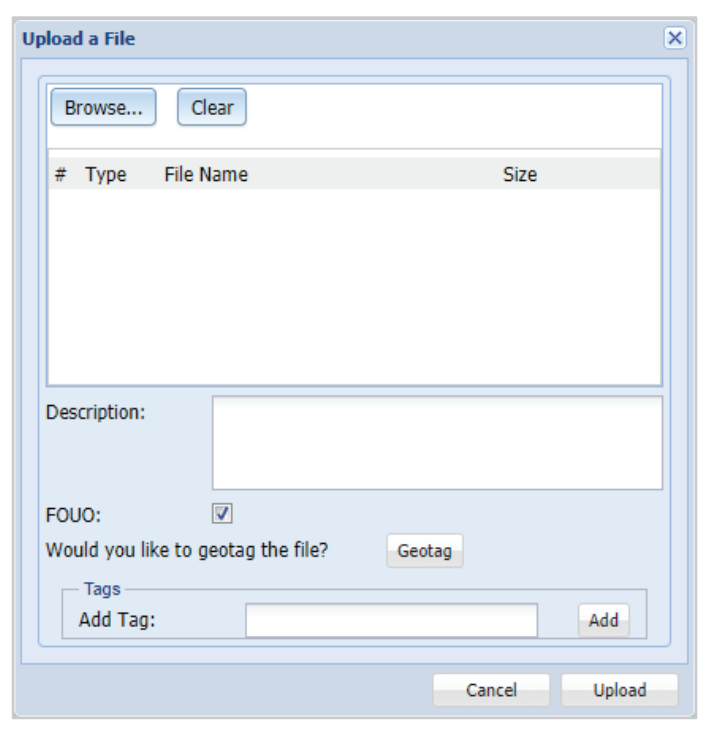

Choose the desired file, describe it, choose whether it is For Official Use Only (FOUO) or not, add tags, then upload the file. Once the file is uploaded, it will appear on the Videos tab. Click the video, then when the player loads, right click the player and select Copy video address. Different browsers have different variants of this option. For example, the right click menu on Internet Explorer shows Copy video URL (Figure 24), but they all are very similar and do the same thing.

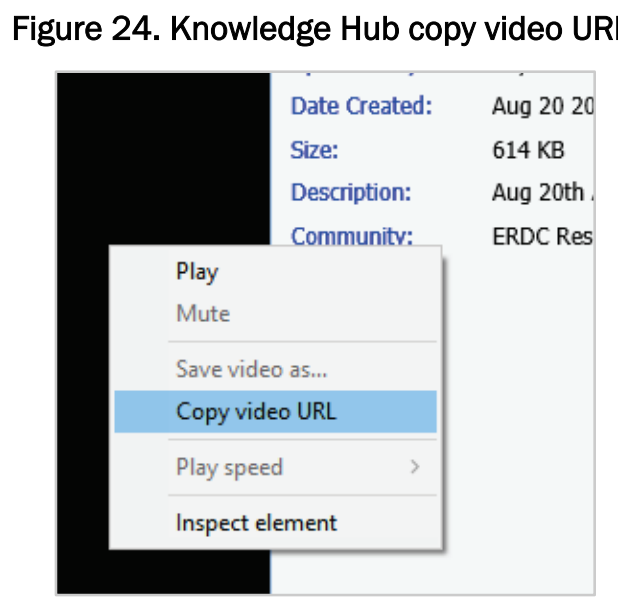

To embed a Knowledge Hub video onto a panel, paste the video's MP4 URL into the Video box on Discover ERDC like before.

4. Picture - This is the box used when an image needs to be placed in a panel. If an image has already been assigned, a Remove button will appear. 
The image must be removed prior to adding a new one. Choose a file from your computer using the Choose File button. Please note, if the picture chosen to post is hosted online, save it to your computer first before attempting to add the image. The image file type must be png, gif, jpg, or jpeg. The chosen file will be uploaded to the site after the changes have been saved and published. The system will automatically rescale the image width-wise to fit inside the panel. After the picture has been chosen, a descriptive text must be added to the Alternative text. This text will be used by screen readers, search engines, or in place of the image when it cannot be loaded. This field is only required when adding an image to a panel.

5. Picture Link - This is simply the internet location that the user will be sent to when the pictured is clicked. Linking a picture is not required, but is available if needed. This can be a link to other internal content, or a link to anywhere on the internet. The box is content aware, so when the title is being typed of an internal page for example, it will auto populate. Be careful when linking to external content to include the http:// (or https://) in front of the link.

6. Events - Events are exactly what they sound like; noteworthy occasions that will occur in the future. They are styled to look like calendar dates with an event date, title, and description. Click on the Add Event button to add a new event to the panel, fill in the date, title, and description fields. Multiple events can be added, as seen earlier on the Events panel.

7. Body - The body of a panel consits of the text that goes under a video or picture. The body can include text, bulleted and numbered lists, links, etc. Body content can also be aligned left, center, right, or justified. Formatting changes made in this section are converted to HTML code in the background. If comfortable reading and editing HTML, the Source button can be used to view the source code behind the body content (Figure 25). 
Figure 25. Show the HTML source of the body.

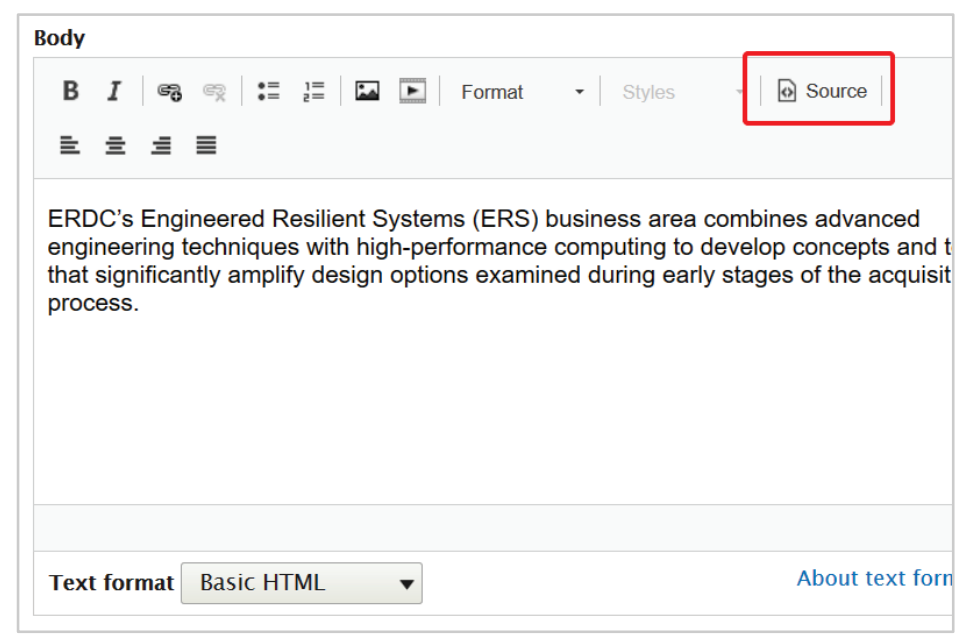

Video and Picture embedding can also be done from the body section, although this is not recommended. Clicking the picture or video toolbar buttons brings up a dialog box for options. Pictures have the option to for a caption to be added beneath them, and alignment options for left, right, center, or none. Since the picture will be added to a panel, none of the alignment options apply if the picture is wider than the panel. If the picture is not as wide as the panel, the alignment options will apply to the picture.

Figure 26. Picture and video embedding.
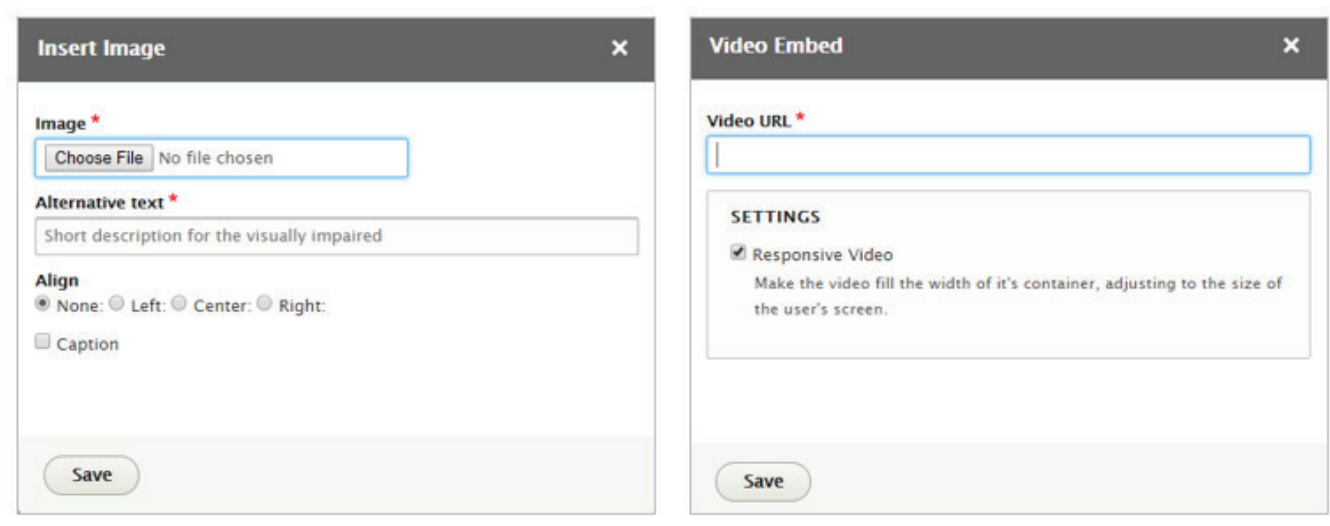

8. Links - These are the link buttons discussed previously. They are web links that are styled to look like buttons. The parts of each link: URL, Link text, and ERDC Only Box. URL is the internet location where the user will be directed when the button is clicked. This can be a link to other internal content, or a link to anywhere on the internet. The box is content aware, so when typing the title of an internal page for example, it will auto populate. 
Be careful when linking to external content to include the http:// (or https://) in front of the link. The second part, Link text, is the plain text that will be shown on the link button; no styles or anything associated with it, just plain text. The last part, ERDC Only is where links are marked to notify users that they internal to the ERDC network. If the link is only accessible to ERDC employees, then check this box. An ERDC branding marker will be placed to the left of these link buttons. Multiple link buttons can be placed on the panel. Use the Add another item button at the bottom of the links section to add an additional link to the panel as shown in Figure 27.

Figure 27. Add another link button.

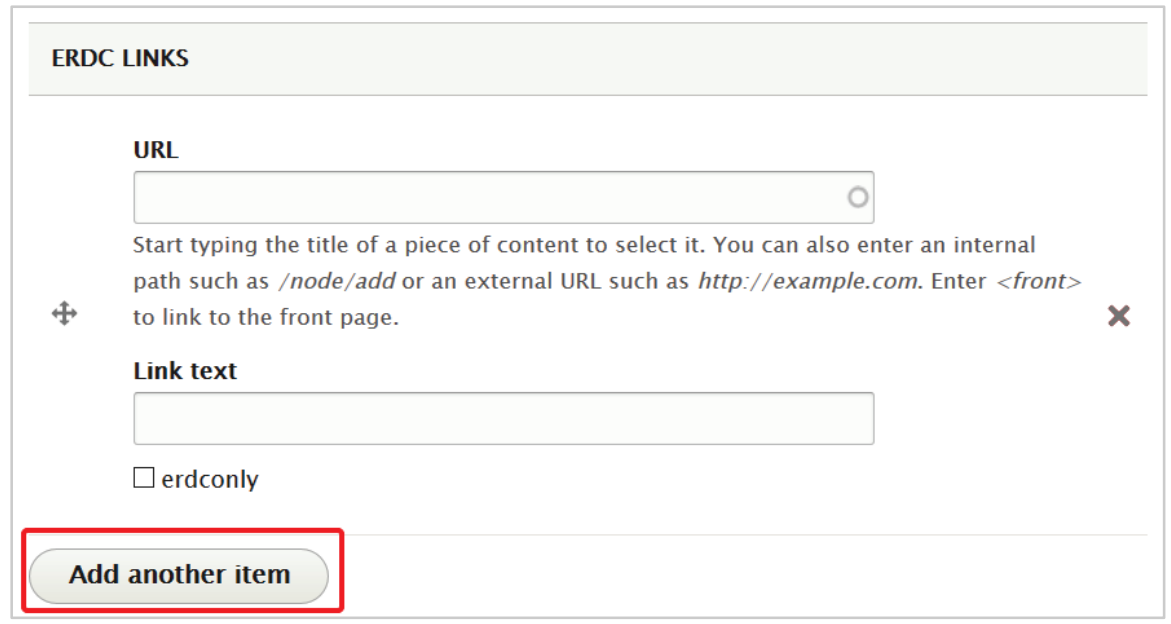

9. Placement - This box will only be visible to administrative users. It rearranges the panels, so please do not use it unless you know exactly what you are doing.

10. Published - Check this box to show the panel on the landing page. If the panel does not need to be shown, uncheck the box.

11. Published Message - The CMS has a feature that allows content to be restored back to a previous state. These states are saved as "revisions." Every time content is edited, there will be an opportunity to save it as a revision. Creating a revision means that temporary changes can be made to the slide, then at a later date, it can be reverted back to a previous state without having to make further changes. The last saved date (if there is one) and the last author (if there is one) will be seen here as well. The checkbox next to Create new revision is checked by default, and it should normally stay checked. But, if for some reason a revision does not need to be saved, uncheck the box. Regardless of the checkbox status, a log message is required. This helps others know what was done when the 
content was edited. Make sure to provide a good description of what was changed. This makes it easier to determine which revision is needed.

12. Action Buttons - Use the Save button to save changes, Preview to see what changes will look like before saving, and Delete to completely delete the content. It is recommended to use the preview before publishing changes in order to see what the slide looks like before publishing to the live site. That way if something does not look correct, it can be changed before it goes live. Clicking the Save button immediately publishes the changes to the live site when the Published box is checked, so make to preview first.

Saved revisions are on the Revisions tab inside the panel editor, just like they were for carousel slides. They function in the exact same way.

\section{Content pages}

Content pages are in essence a web page just like any other on the internet. They can contain any type of content a normal web page would contain; text, videos, pictures, lists, etc. Editing content pages is very similar to editing panels, except the space limitations placed on the panels are not a concern here.

Not all roles are assigned a page to maintain. If assigned a page maintenance role, the page will appear in the CMS. The pages assigned to you will be seen labeled Page under the Content Type column in the content management area.

To edit a page, click the Edit button in the Operations column. This brings up the Edit Page window and opens the Edit tab. Pages are fairly simple as there are only two fields available to edit:

1. Title - This text is shown at the top of the page in large, bold font. Treat this text as a heading for the page. This is a required field as indicated by the red asterisk.

2. Body - The body of a page is the page itself. It is everything that is shown on the page between the page header and the footer section (minus the page the title). In the About ERDC example, a styled text in headings and paragraphs, an image, and a bulleted list have been added. The editor toolbar works exactly the same as the panel body editor. 
Consider the following page editing exercise. The bulleted list items under the heading Business Areas need to be linked to the pages for those business areas. Inside the editor, highlight the text Military Engineering in the first bulleted list and click the Link button (Figure 28).

Figure 28. Adding a link to a content page.

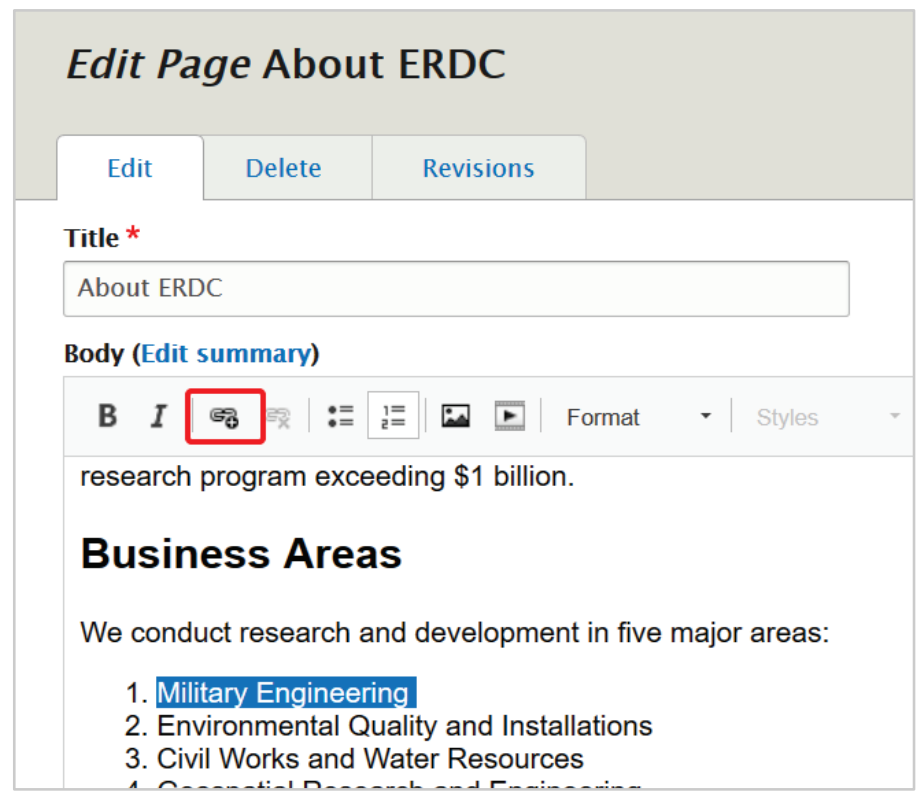

As seen in Figure 29, a dialog box will appear where the URL will be entered. This box is content aware just like when adding links to a panel. Just start typing the name of an internal page, and it will show up in the box.

Figure 29. Add link dialog box.

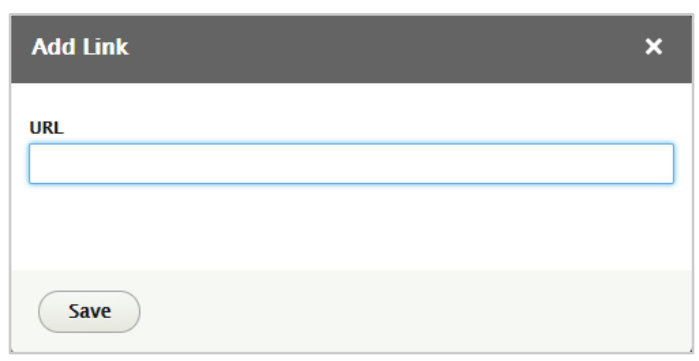

The newly created link will appear as blue underlined text in the body editor (Figure 30). 
Figure 30. Completed page link.

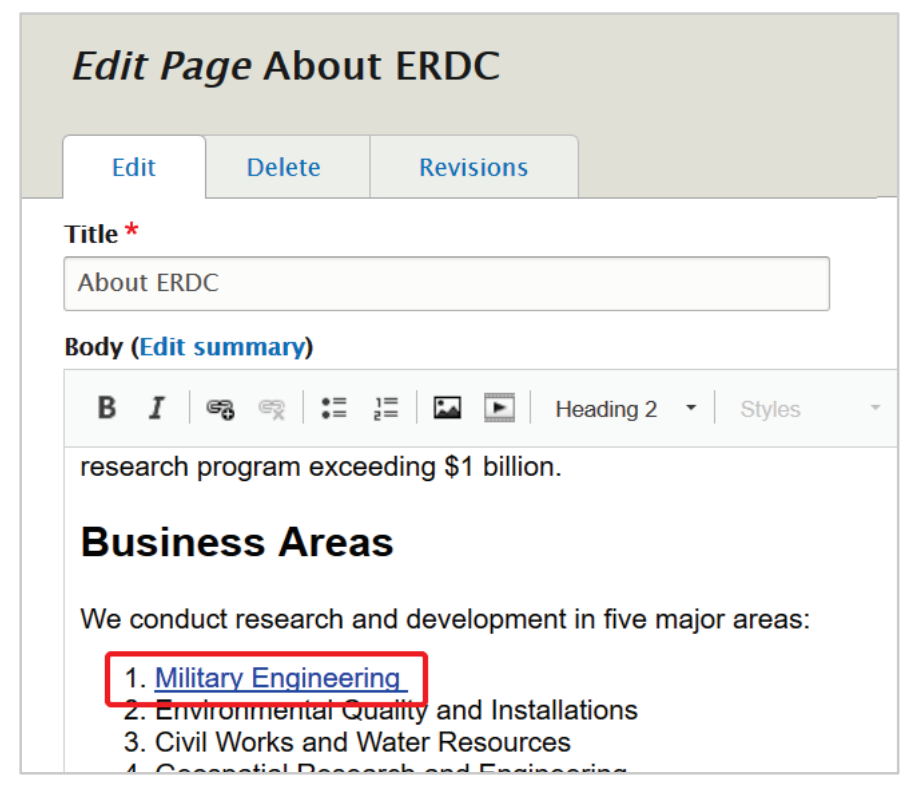

Body text can be styled using the toolbar buttons for bold, italic, align left, align right, align center, and align justified. There is an additional font style function under the Format toolbar button. Inside this text styling function, numerous pre-defined text formats can be chosen. Select the text to be styled first, then use the drop-down menu to select a text format (Figure 31). The format will be applied to all selected text.

Figure 31. Predefined text formats.

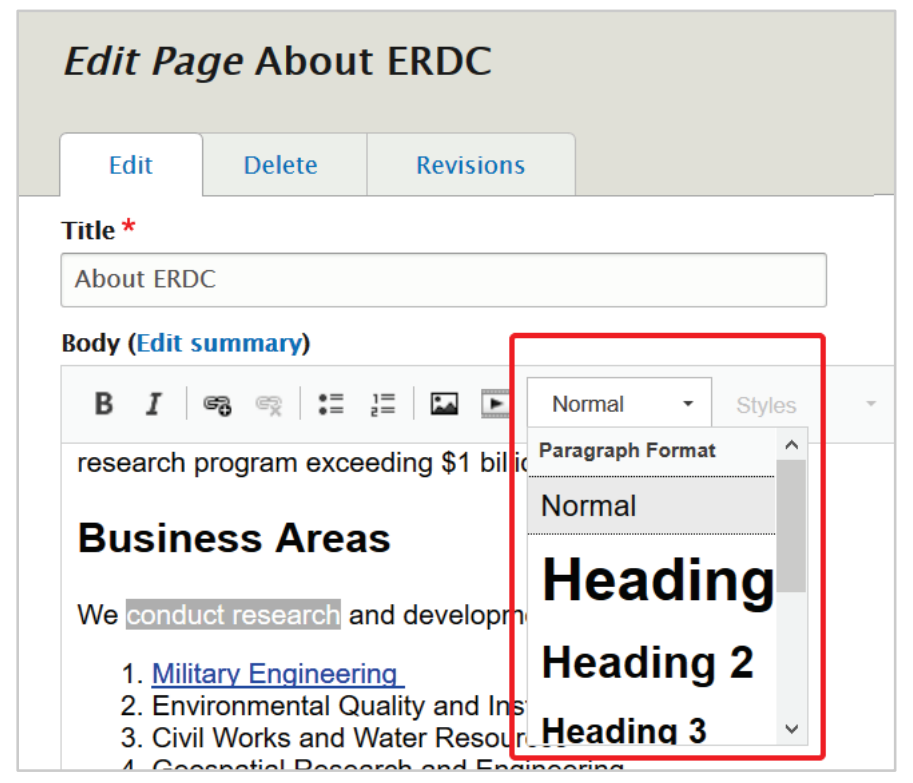


Formatting changes made in this section are converted to HTML code in the background just like in the panels. If comfortable reading and editing HTML, the Source button can be used to view the source code behind the body content (Figure 32).

Figure 32. Page source code toggle.

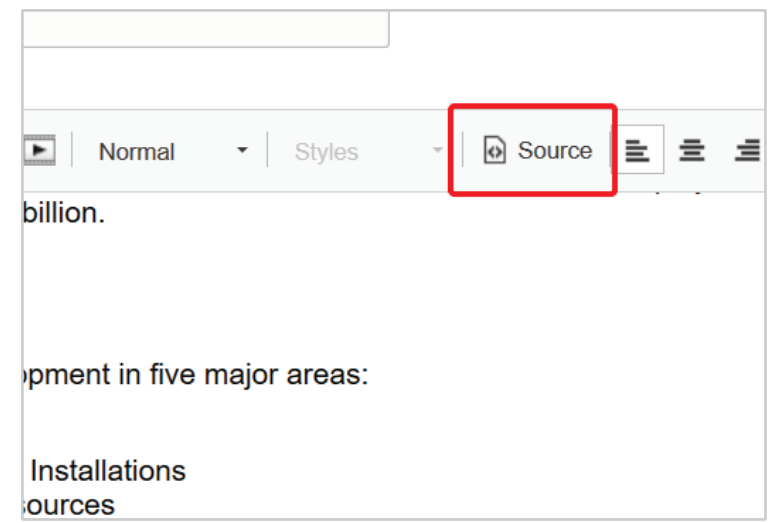

Pictures and videos can also be inserted into the body of a page in a similar manner as panels. Recall that pictures on panels are sized to fit the panel width wise because of the space restrictions. Pages do not have those size restrictions, so pictures and videos have some properties that must be set whenever they are added to the page. Clicking the picture or video toolbar buttons will bring up a dialog box for options. Pictures have the option to add a caption beneath them, and alignment options for left, right, center, or none. Videos have the option to make them responsive to the size of the container they are inside and whether or not to autoplay the video when the page loads.

Figure 33. Insert image and video dialog boxes.
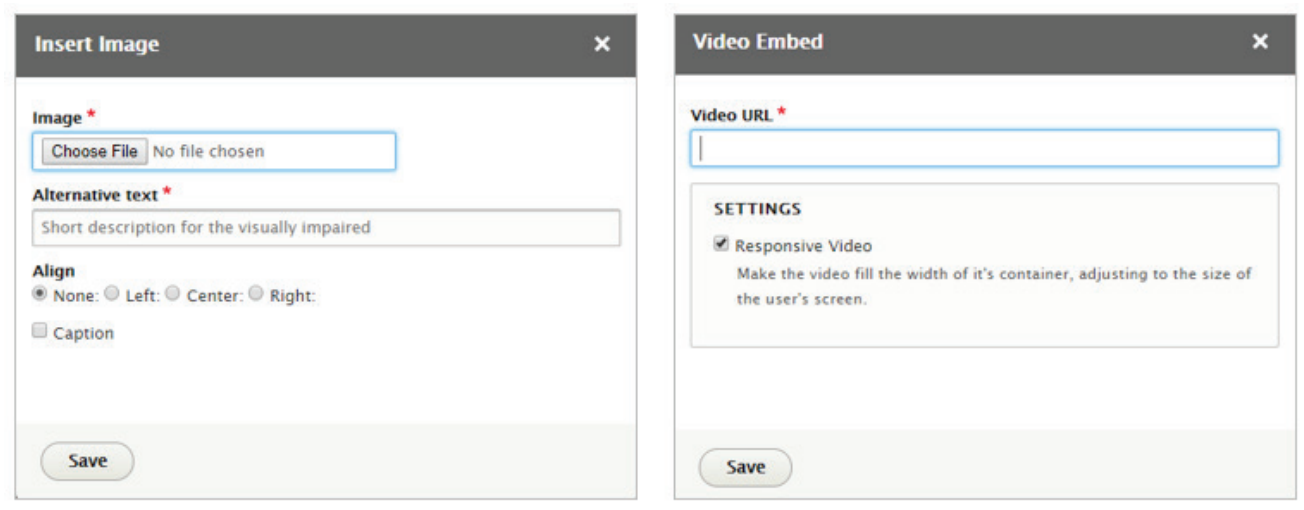
After a picture or video is added to the page, hovering the mouse over it allows the vertical alignment to be changed. As show in Figure 34, grab the Plus sign at the top right of the picture or video and drag it up or down the page. This does not allow the horizontal alignment to be changed. The picture or video must be clicked to select it, then use the alignment toolbar buttons to accomplish the desired horizontal alignment change (Figure 35).

Figure 34. Vertical alignment adjuster.

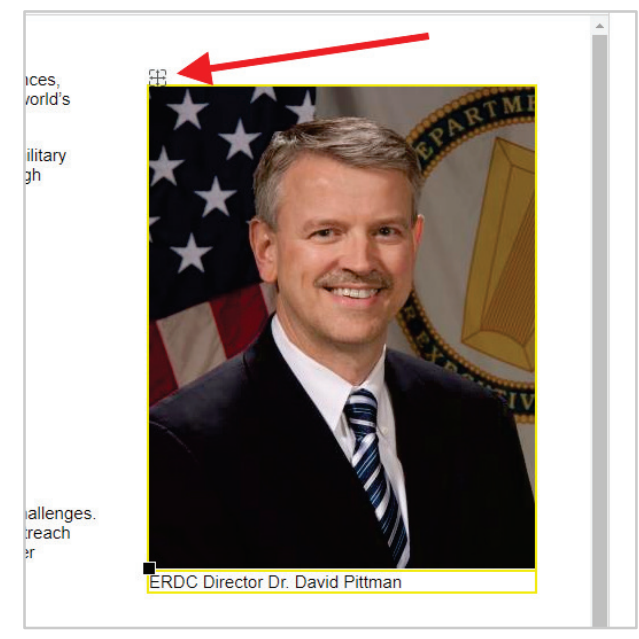

Figure 35. Horizontal alignment toolbar buttons.

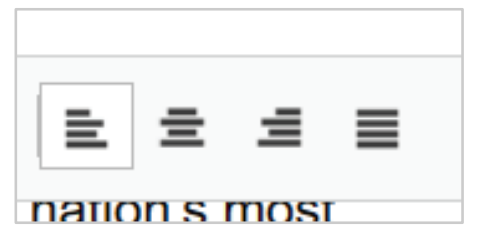

Finally, when all edits are completed, the page can be previewed by clicking on the Preview button at the bottom of the screen. It is recommended to use the preview before publishing it to the live site. That way if something looks incorrect, it can be changed before it goes live.

Pages also have Revisions just like all other content types. They work the same way; use the Published box at the top right of the editor, and the Revisions tab at the top left. As mentioned before, it is always recommended to create a revision when editing content. The Create new revision checkbox is checked by default, so unless manually unchecked, a revision will be created.

Only a small number of roles have the ability to add new pages to the system instead of just editing exisiting pages. Creating a new page brings 
up the same editor window that editing a page does, except the form will be blank. Use the +Add content button at the bottom of the main CMS screen to add a new page (Figure 36).

Figure 36. Add new content button.

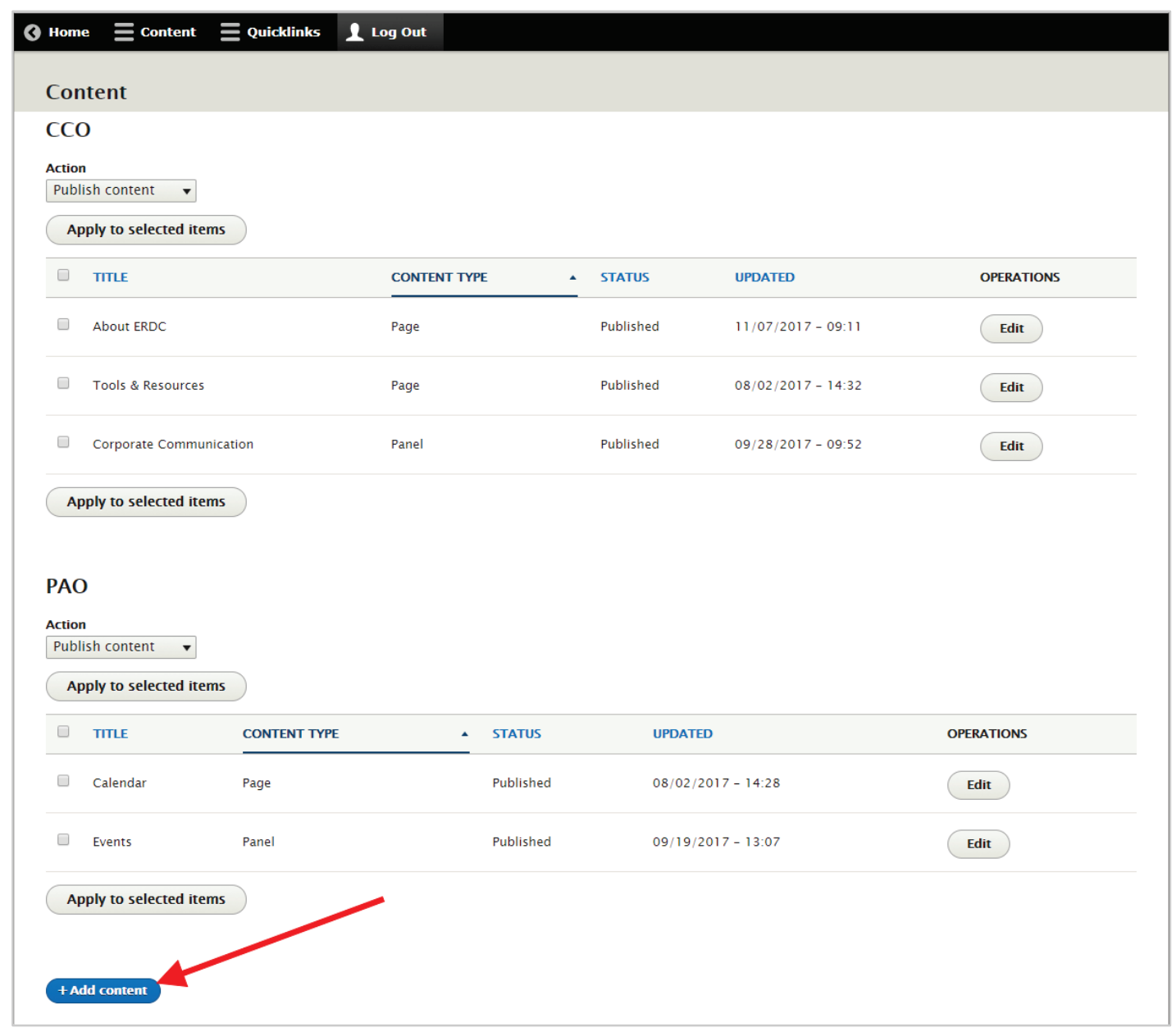

Enter content that should be included on the page in the editor as previsouly discussed, then save and publish the content. The only difference in the form is the addition of taxonomy permission. It is a series of check boxes that allows the page creator to assign the edit role to another group within the system (Figure 37). 
Figure 37. Page editor taxonomy permissions.

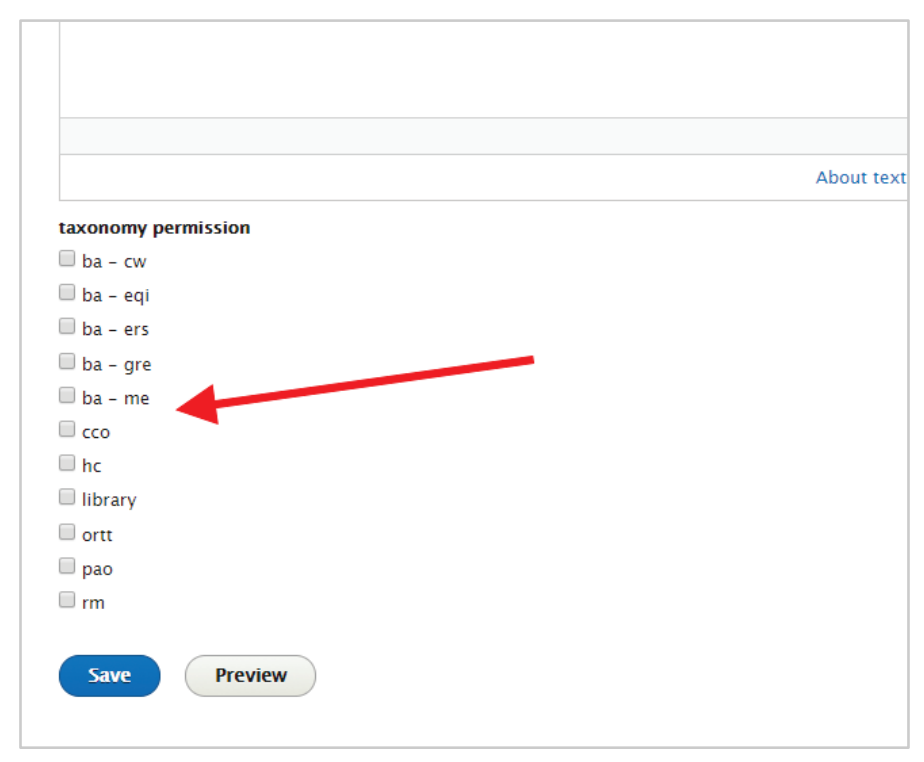

For example, if $\mathrm{CCO}$ adds a new page and wants the library group to maintain the page, the box next to library would be checked to assign the edit role to that group. More than one taxonomy permission may be added to a page, so check all roles that apply. Make sure to enter a revision log message, then preview and save the page.

Again, very few KMRs have the ability to create content, so it is likely the content creator will never be used.

\section{Quicklinks and social icons}

The final content management topics are two less commonly edited areas of the site; quicklinks and social icons. Quicklinks are the links at the bottom left of the landing page. Also located in this area are the social media icons (Figure 38). 
Figure 38. Quicklinks section at the bottom of the landing page.

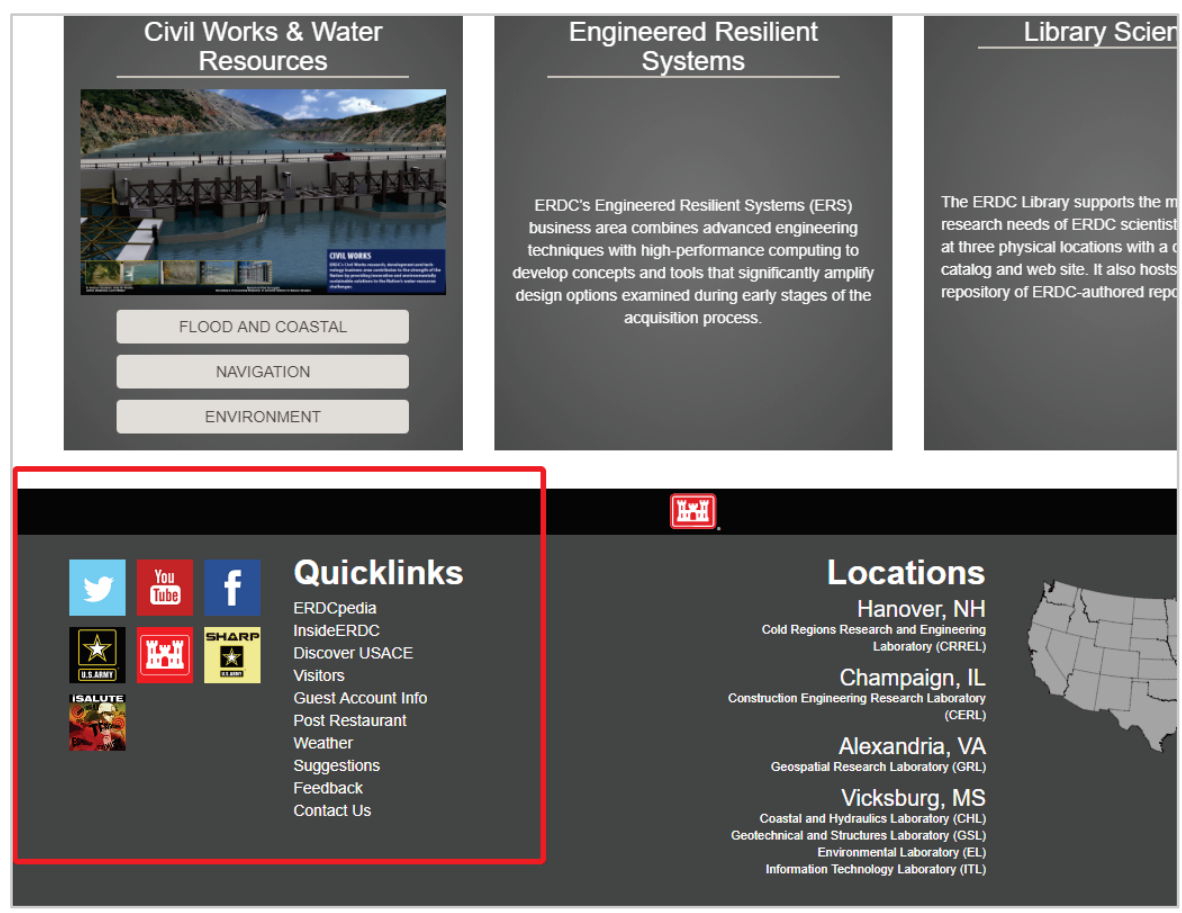

Quicklinks are provided as a convenience for visitors to quickly gain access to commonly requested functions. Social icons link users to ERDC's external social media accounts. There are also icons for non-social media sites such as SHARP and iSALUTE.

As seen in Figure 39, the quicklinks editor can be accessed from the CMS bar at the top of the screen. If Quicklinks cannot be seen in the CMS bar, then you are not currently assigned that role.

Figure 39. Quicklinks button.

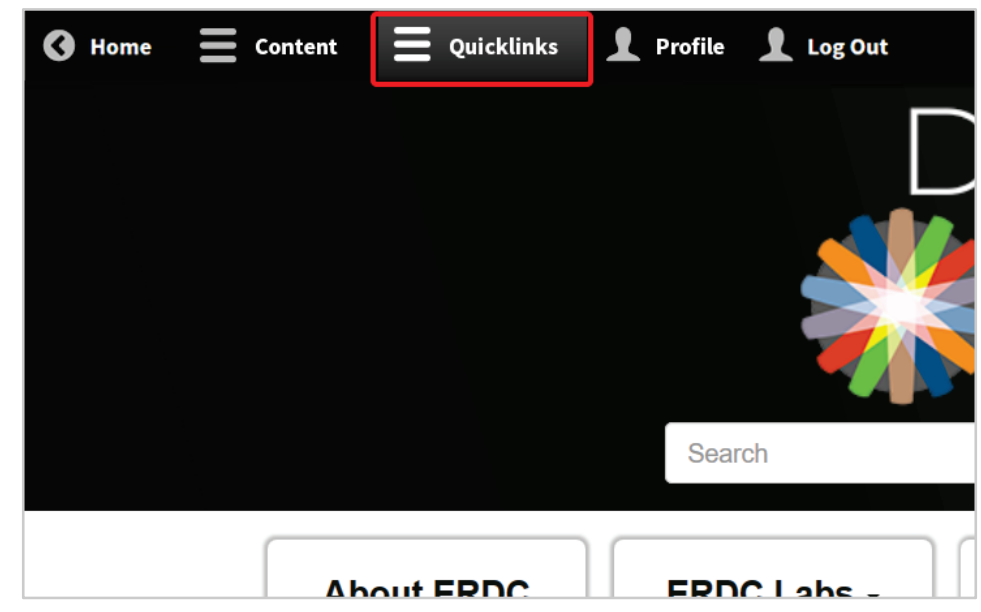


Editing quicklinks is a very simple process. In the quicklinks editor, all current quicklinks can be seen (Figure 40). They are listed in the same order as seen on the landing page. A link can be turned on or off using the Enabled checkbox or the link text can be edited by clicking the Edit button.

Figure 40. Quicklinks editor.

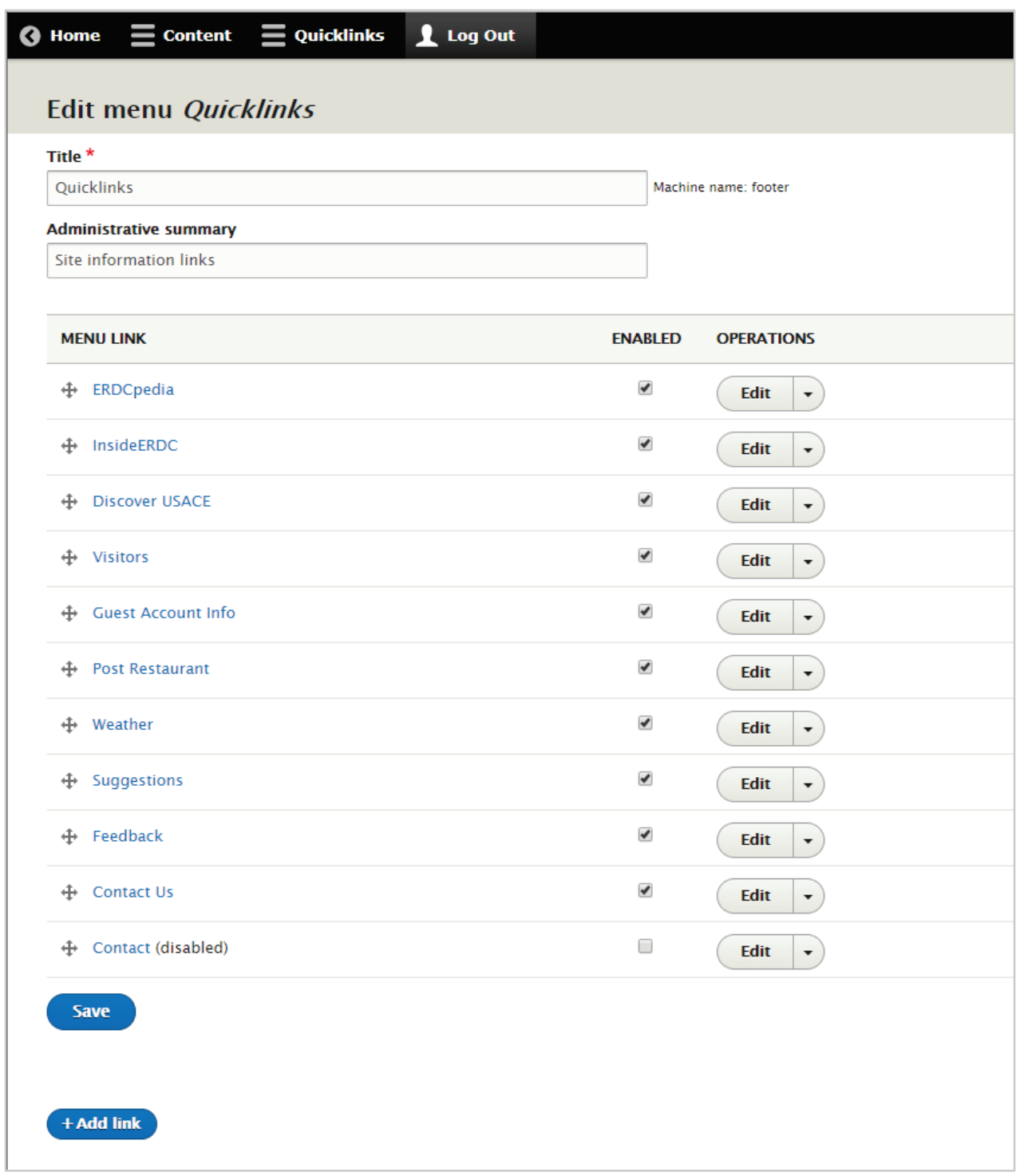

In the link editor, the concern only lies with the Menu link title, Link, and Description fields. The other fields deal with expanding menus, which are not used on DiscoverERDC. Menu link title and Link are required fields. Description is optional, but if text is supplied, it will show as a tool tip when the mouse is hovered over the link. The Link field is the URL where the user will be directed. This box is content aware, so if 
linking to another page within DiscoverERDC, simply start typing that page's title and select it from the list that appears. If linking the user to an external site, make sure to enter http:// (or https://) in front of the address.

Figure 41. Quicklinks editor components.

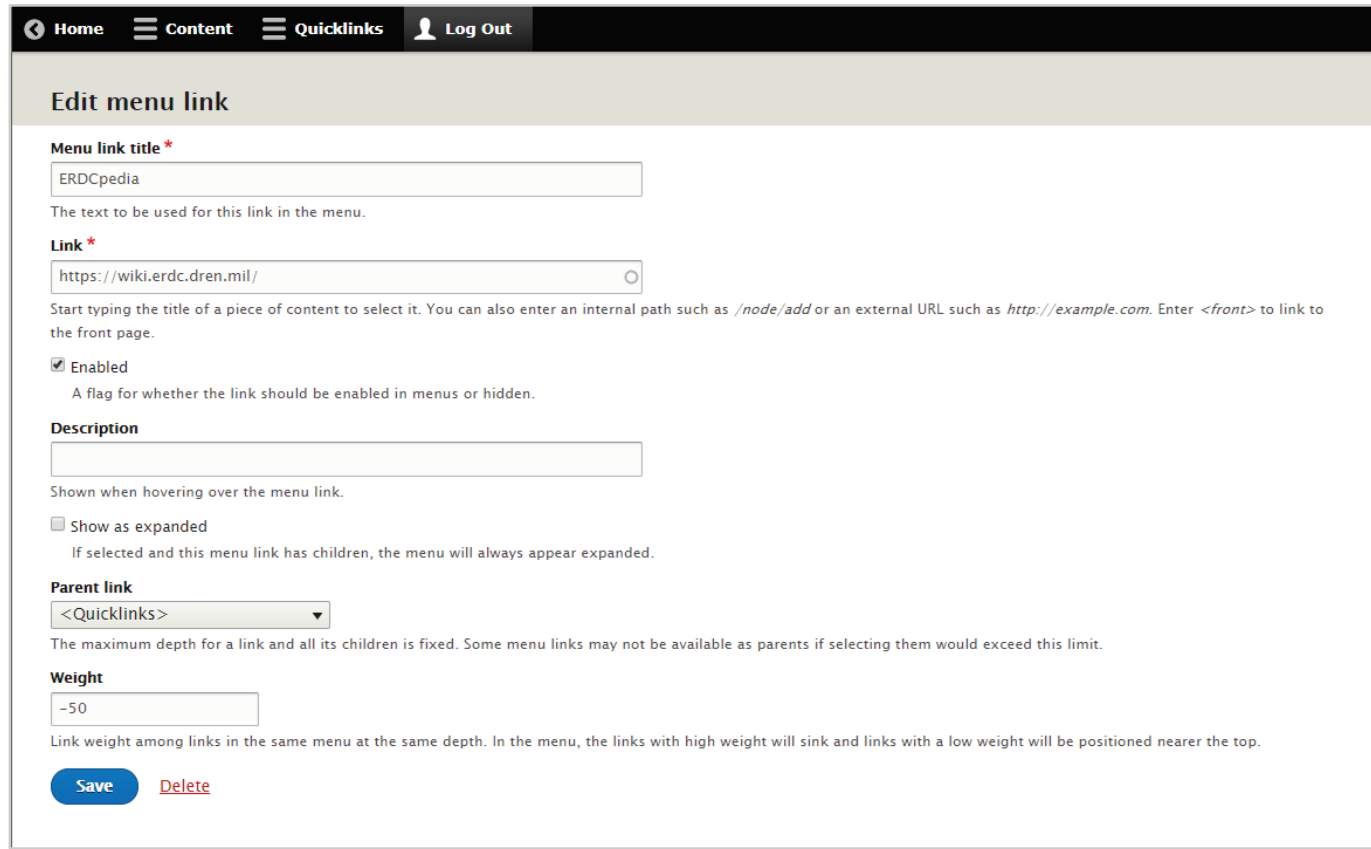

Once the link changes have been saved, you will be directed back to the quicklinks editor. As mentioned previously, links are listed in the order they will appear on the landing page. If the links need to be reordered, use the mouse to grab the plus sign to the left and drag the link up or down the list. To add a new link to the list, click the +Add link button at the bottom of the screen. This lead to the link editor where the new link can be defined.

Using the CMS, social icons can be added, edited, or removed by administrative level users . If assigned to maintain social icons, they will be seen on the CMS screen. They will appear in the table as Social icon under the Content Type column (Figure 42). 
Figure 42. Social icons in the content editor.

\section{(3) Home $\equiv$ content $\mathcal{L}$ Profile $\Omega$ Log Out}

$\square \quad$ TITLE

$\square \quad$ Twitter Icon

$\square \quad$ Youtube Icon

$\square \quad$ Facebook Icon

$\square \quad$ US Army Icon

$\square \quad$ ACE Icon

$\square \quad$ SHARP Icon

$\square \quad$ Salute Icon

\begin{tabular}{l} 
CONTENT TYPE \\
\hline Social Icon
\end{tabular}

Social Icon

Social Icon

Social Icon

Social Icon

Social Icon

Social Icon
STATUS

Published

Published

Published

Published

Published

Published

Published
UPDATED

$09 / 28 / 2018-15: 05$

$09 / 28 / 2018-15: 05$

$09 / 28 / 2018-15: 05$

$09 / 28 / 2018-15: 05$

$09 / 28 / 2018-15: 05$

$09 / 28 / 2018-15: 05$

$09 / 28 / 2018-15: 05$
OPERATIONS

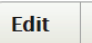

Edit

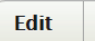

Edit

Edit

Edit

Edit

Click the Edit button to access the social icon editor. From the editor, the Title and Alternative text will be entered, then choose an image and enter a URL.

Figure 43. Social icon editor fields.

\section{(6) Home $\equiv$ content $\Omega$ Profile $\Omega$ Log out}

Edit Social Icon Twitter Icon

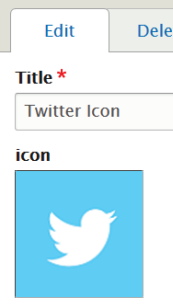

Alternative text *

twitter

Short description of the image used by screen readers and displayed when the image is not loaded. This is important for accessibility.

圆 twitter_1_0.png (2.92 KB) Remove

url *

https://twitter.com/ArmyERDC

Start typing the title of a piece of content to select it. You can also enter an internal path such as

/node/add or an external URL such as http://example.com. Enter <front > to link to the front page.

$\square$ Published

Published

Last saved: 09/28/2018 - 15:05

Author:

$\square$ Create new revision

Revision log message *

Briefly describe the changes you have made.

Revisions for social icons work exactly the same as previously discussed for other areas. Save and publish the icon after previewing. 


\section{Conclusion}

Maintaining ERDC's knowledge is essential to the execution of research projects and the future success of the lab. The role of a KMR is vital to this effort. This guide should help utilize the powerful features of the CMS, so the content can easily be managed. If there are any future questions or issues, see the Points of Contact in Appendix C. 


\section{Appendix A: System Roles}

Table 1. System roles.

\begin{tabular}{|c|c|}
\hline Role & Content \\
\hline \multirow{5}{*}{$\mathrm{CCO}$} & About ERDC (page) \\
\hline & Tools \& Resources (page) \\
\hline & Corporate Communication (panel) \\
\hline & Can create new pages \\
\hline & Can set who can edit a page (field_taxonomy_permission) \\
\hline \multirow{3}{*}{ ORTT } & Support Organizations (page) \\
\hline & Tools \& resources (page) \\
\hline & Quicklinks \\
\hline \multirow{5}{*}{ PAO } & About ERDC (page) \\
\hline & Tools \& Resources (page) \\
\hline & Announcements (panel) \\
\hline & Can create new pages \\
\hline & Can set who can edit a page (field_taxonomy_permission) \\
\hline RM (Manpower) & ERDC in the NEWS (PDF document) \\
\hline $\mathrm{HC}$ & Human Capital (panel) \\
\hline \multirow{3}{*}{ Library } & Post Restaurant (page) \\
\hline & Tools \& Resources (page) \\
\hline & Library Sciences (panel) \\
\hline \multirow{10}{*}{ Support Org } & Safety and Environmental Office (page) \\
\hline & Directorate of Resource Management (page) \\
\hline & Security (page) \\
\hline & Equal Employment Opportunity Office (page) \\
\hline & Office of Counsel (page) \\
\hline & Office of Small Business Programs (page) \\
\hline & Contracting Office (page) \\
\hline & Public Affairs Office (page) \\
\hline & Directorate of Public Works (page) \\
\hline & Tech Transfer (panel) \\
\hline BA - GRE & Geospatial Research \& Engineering (panel) \\
\hline
\end{tabular}




\begin{tabular}{ll}
\hline BA - ERS & Engineered Resilient Systems (panel) \\
\hline BA - ME & Military Engineering (panel) \\
\hline & Civil Works: Flood \& Coastal (panel) \\
BA - CW & Civil Works: Navigation (panel) \\
& Civil Works: Environment (panel) \\
\hline BA - EQI & Environmental Quality \& installations (panel) \\
\hline
\end{tabular}




\section{Appendix B: Troubleshooting}

\section{Clearing browser cache}

Clearing the browser cache solves the majority of issues encountered on Discover ERDC. SSO authentication issues a token to the user's browser that passes their authentication session on to other systems that utilize SSO. This allows them to skip re-entering their CAC PIN over and over again when traversing between systems. The authentication tokens that are issued come with a lifespan of $8 \mathrm{hr}$. After the token is expired, the system will ask for their PIN again. If for some reason the token does not get reissued successfully, the user will see a red box shown in the introduction. Most of the time, these issues are fixable on the client side. The following documentation describes some methods for users to try and repair authentication problems on their computers.

\section{Internet Explorer 9, 10, 11}

1. Select Tools (via the Gear Icon) > Safety > Delete browsing history...

(NOTE: You can also access this menu by holding Ctrl + Shift + Delete.)

Figure 44. Internet Explorer, step 1.

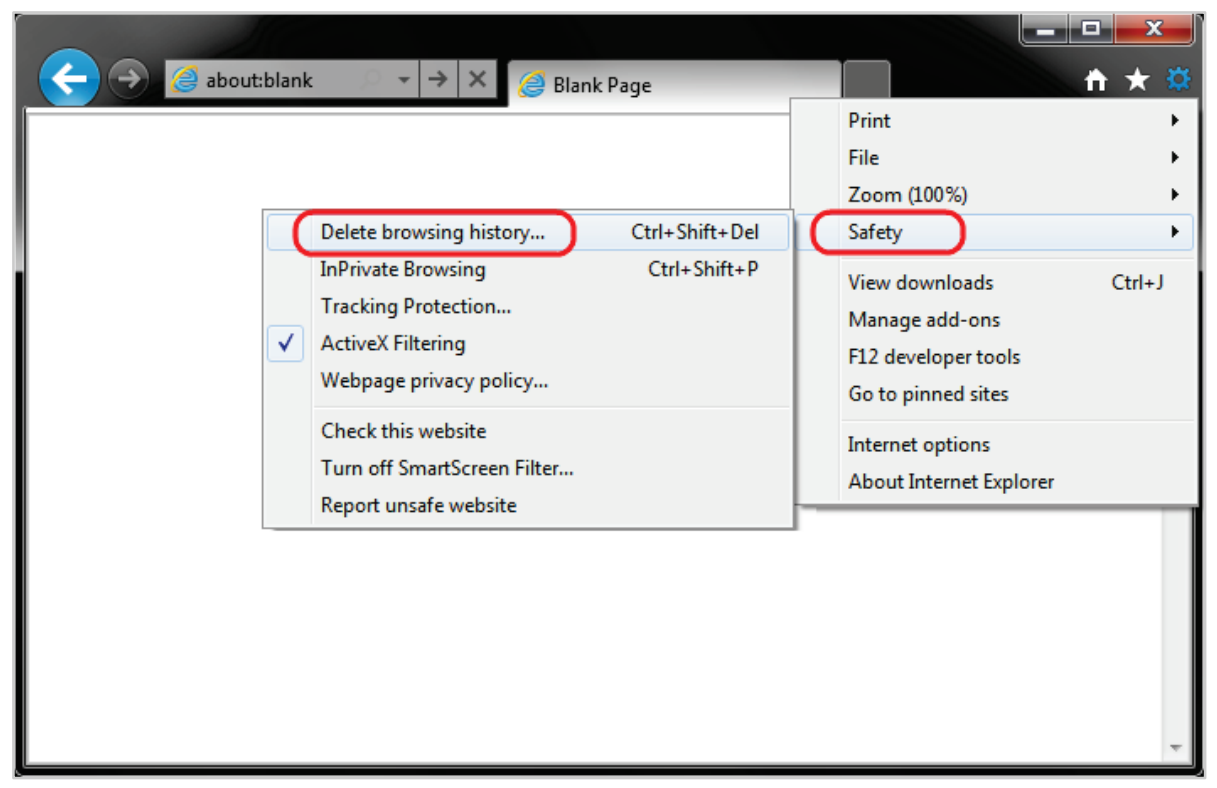

2. Make sure to uncheck Preserve Favorites website data and check both Temporary Internet Files and Cookies then click Delete. 
Figure 45. Internet Explorer, step 2.

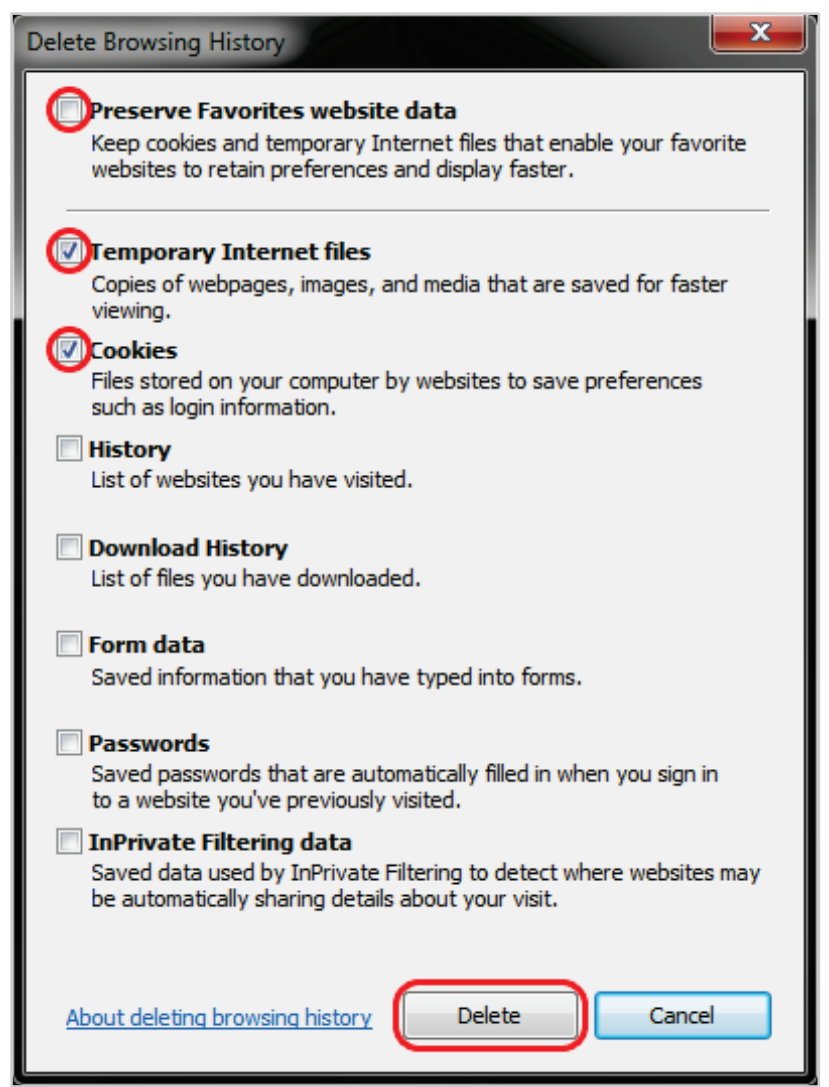

3. A confirmation will be seen at the bottom of the window once it has successfully cleared the cache and cookies.

Figure 46. Internet Explorer, step 3.

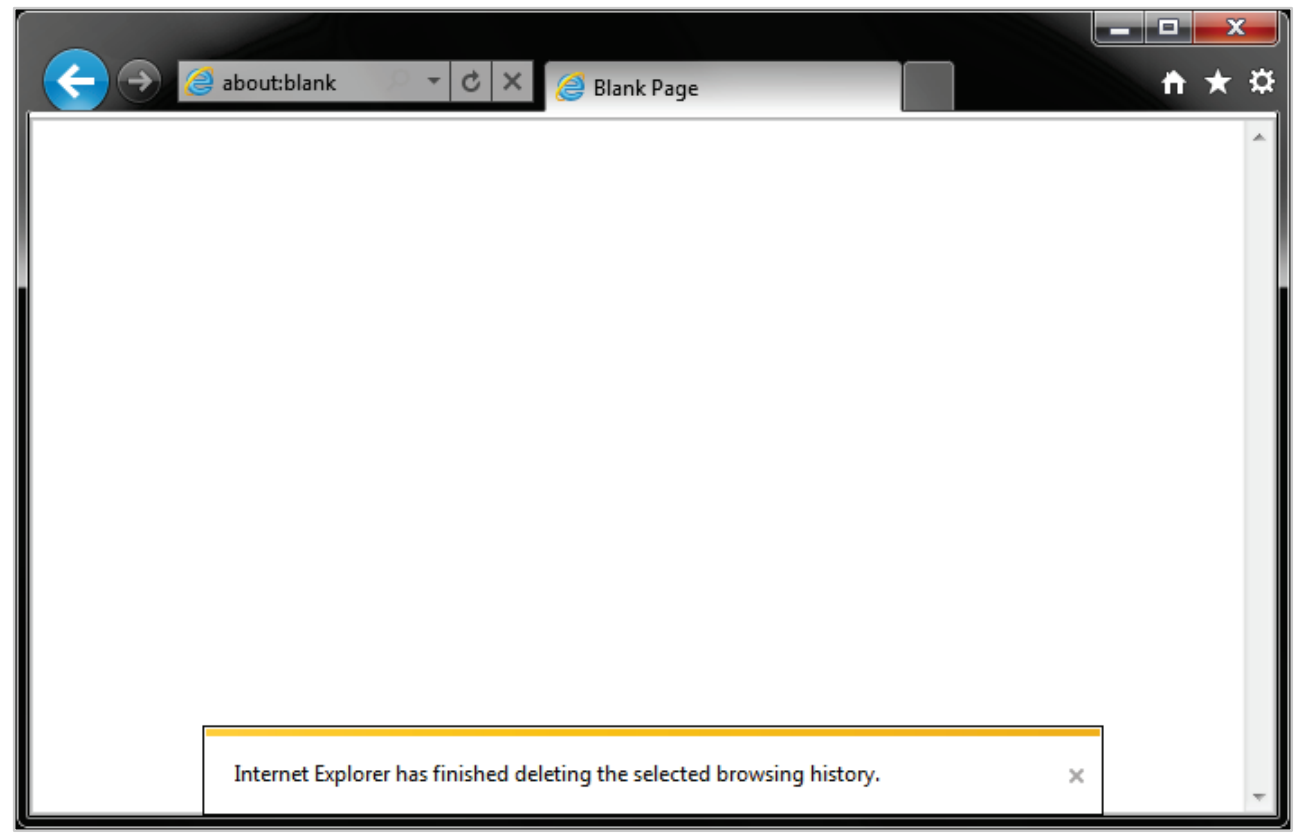


The above procedure for clearing cache and cookies should work for the majority of websites, but certain websites and applications may require a more thorough procedure. If still having issues, try the steps below.

(NOTE: The F12 developer tools in Internet Explorer 11 do not include a cache menu. This process will only work for Internet Explorer 10 or lower.)

1. Close out of Internet Options. Click on Tools and select Developer Tools.

Figure 47. Internet Explorer Developer Tools, step 1.

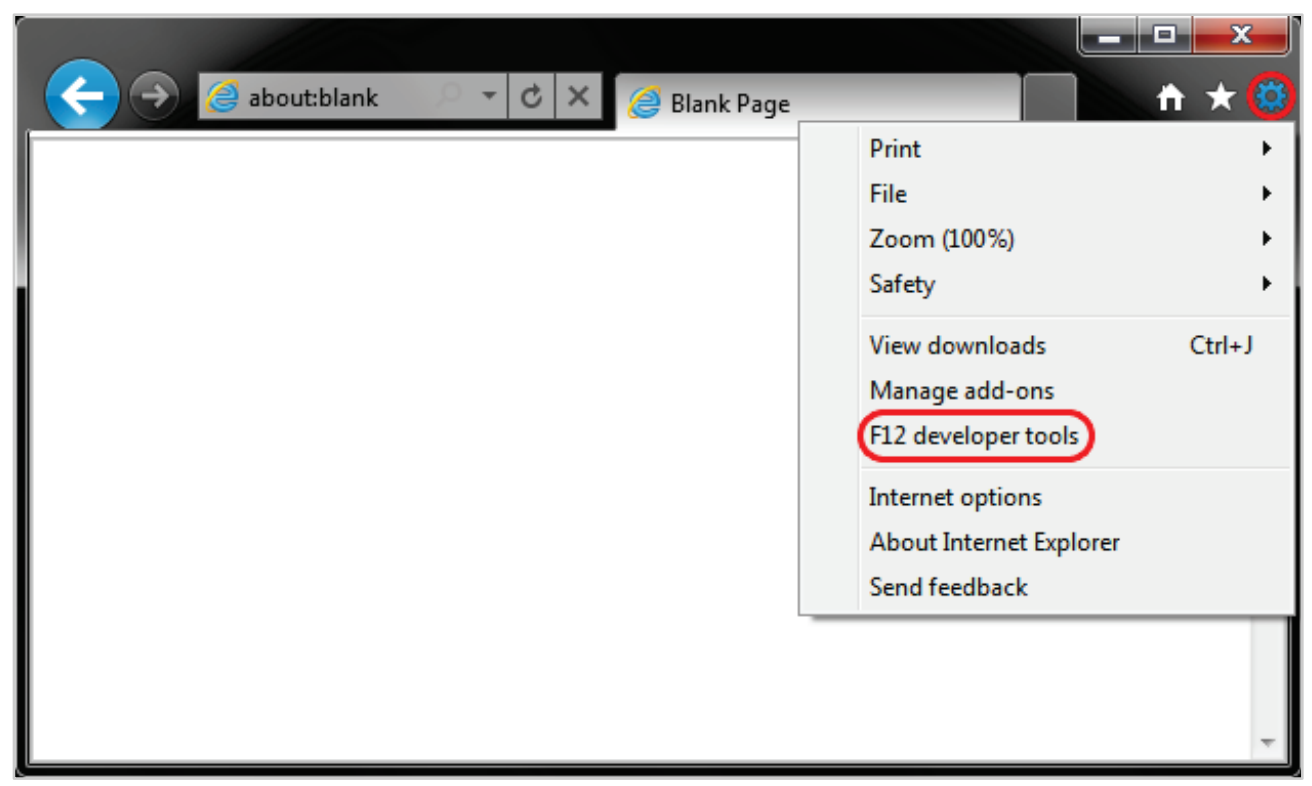

2. In the Developer Tools window, click on Cache and select Clear Browser Cache... 
Figure 48. Internet Explorer Developer Tools, step 2.

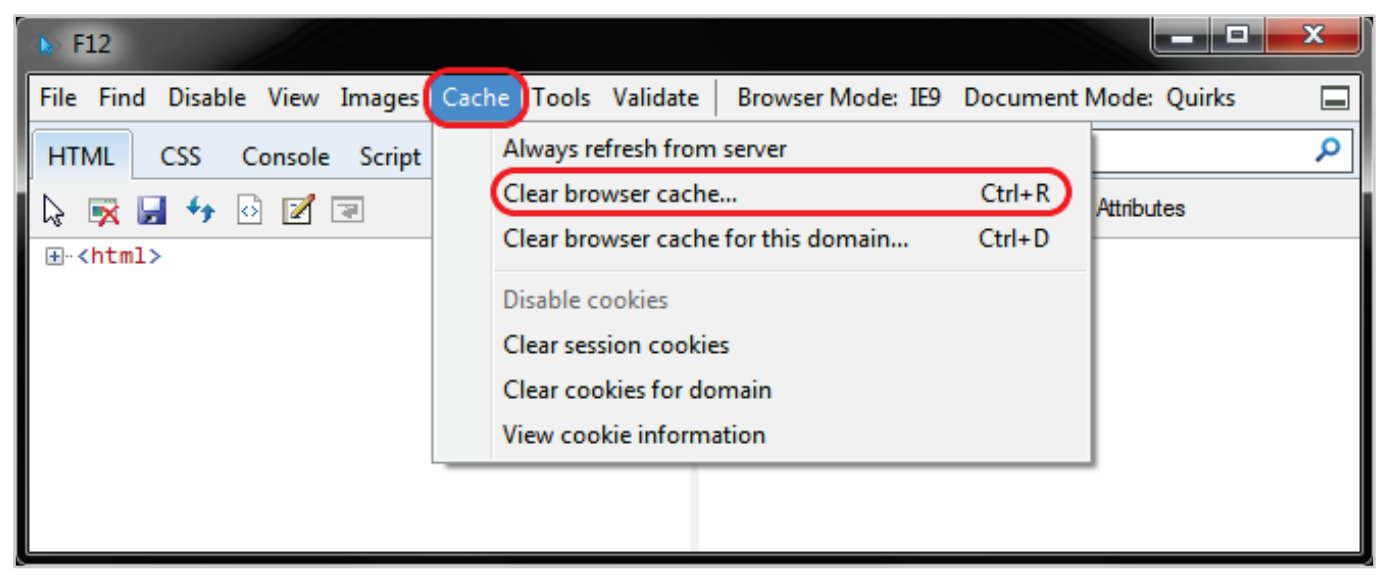

3. Click Yes to confirm the clearing of the browser cache.

Figure 49. Internet Explorer Developer Tools, step 3.

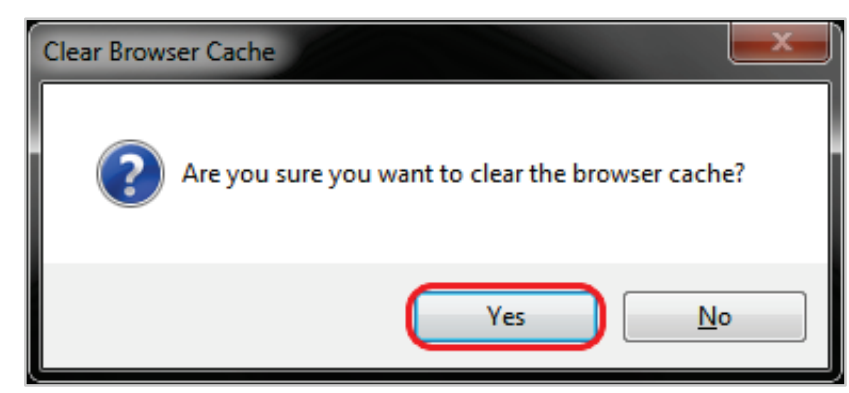

4. Restart Internet Explorer and return to the page you were attempting to access.

\section{Microsoft Edge}

Microsoft Edge, the new browser in Windows 10, allows you to view, manage, and delete browsing history and data.

1. Launch the Edge browser and click on the 3-lined Hub button in the top right corner.

2. Next, click on the clock-shaped History button.

3. Here, the browsing history will be able to be viewed.

If Clear History is clicked, the browsing History, Cookies, Data, Temporary Internet Files, Cache, etc. will be deleted. 
Figure 50. Microsoft Edge, step 1.

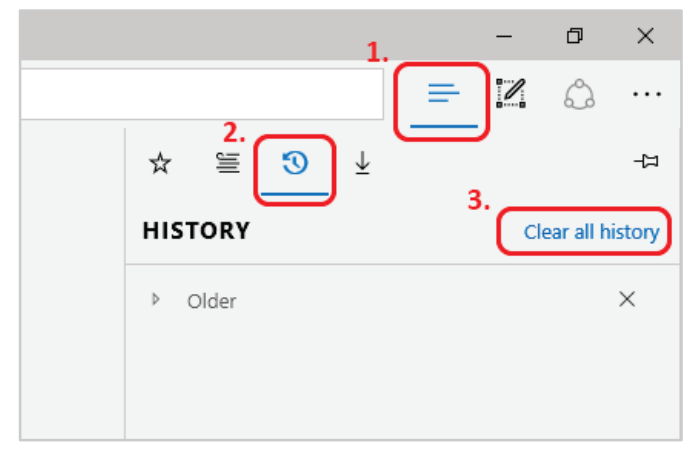

The following items available will be seen:

- Browsing history

- Cookies and saved website data

- Cached data and files

- Download history

- Form data

- Passwords

Select Cookies and saved website data, Cached data and files, and Passwords, then click on the Clear button.

Figure 51. Microsoft Edge, step 2.

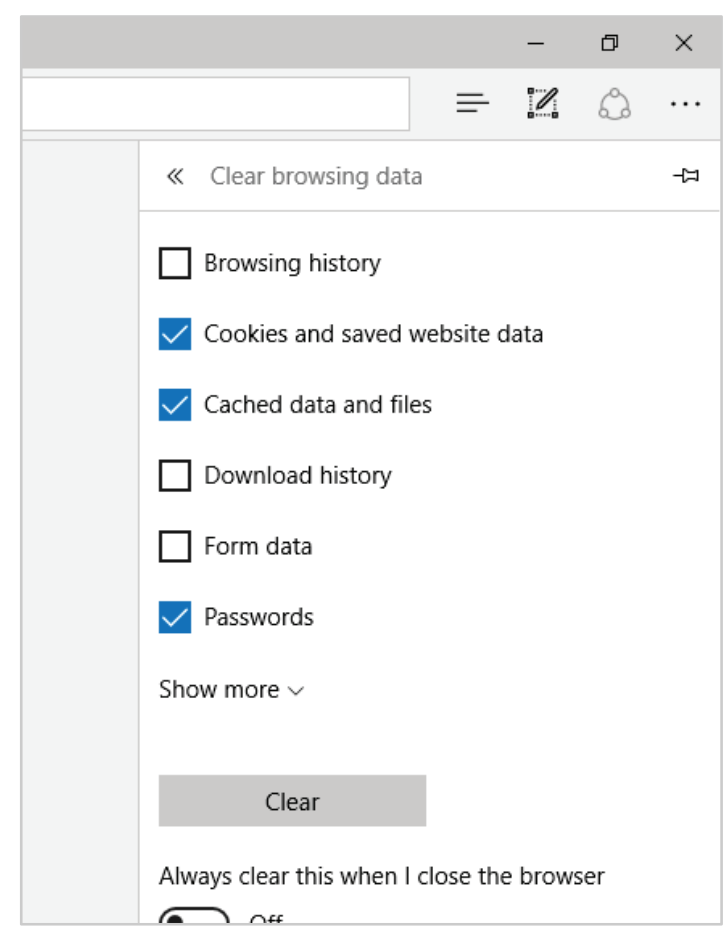


4. Restart Edge and return to the page you were attempting to access.

\section{Google Chrome}

Clearing the browser's cache and cookies means that website settings (like usernames and passwords) will be deleted and some sites might appear to be a little slower because all the images have to be reloaded.

1. Open Chrome.

2. On the browser toolbar, click More $\vdots>$ More Tools ' Clear Browsing Data.

Figure 52. Google Chrome, step 1.

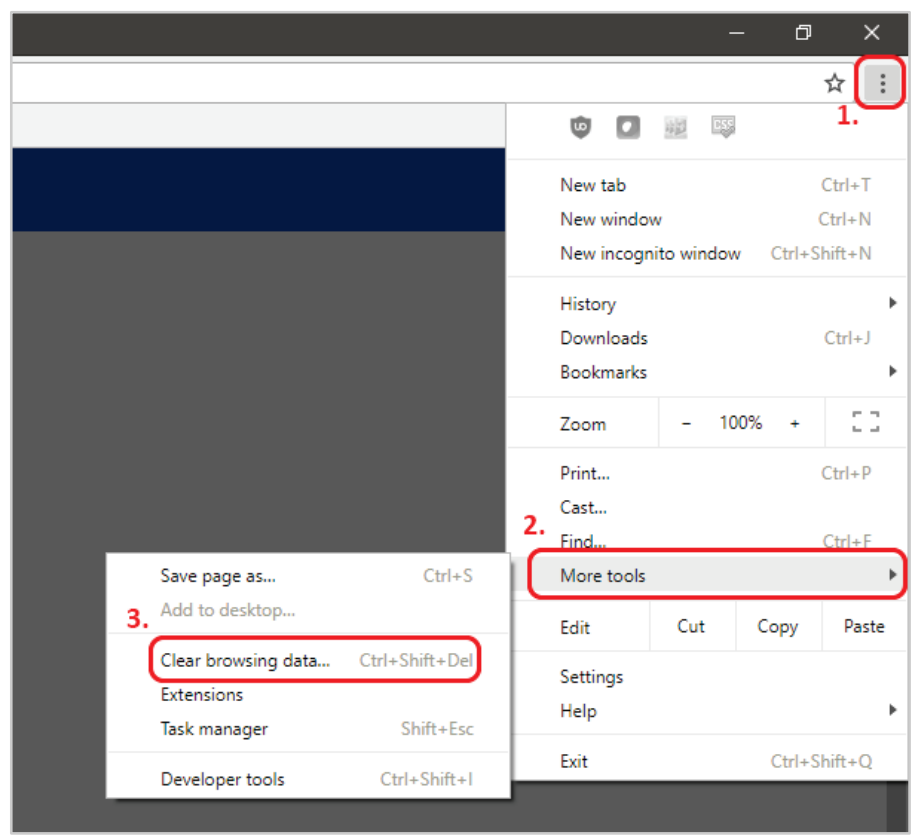

3. In the Clear browsing data box, select the checkboxes for Cookies and other site data and Cached images and files.

4. Use the menu at the top to select the amount of data to delete. Choose All time to delete everything.

5. Click Clear data. 
Figure 53. Google Chrome, step 2.

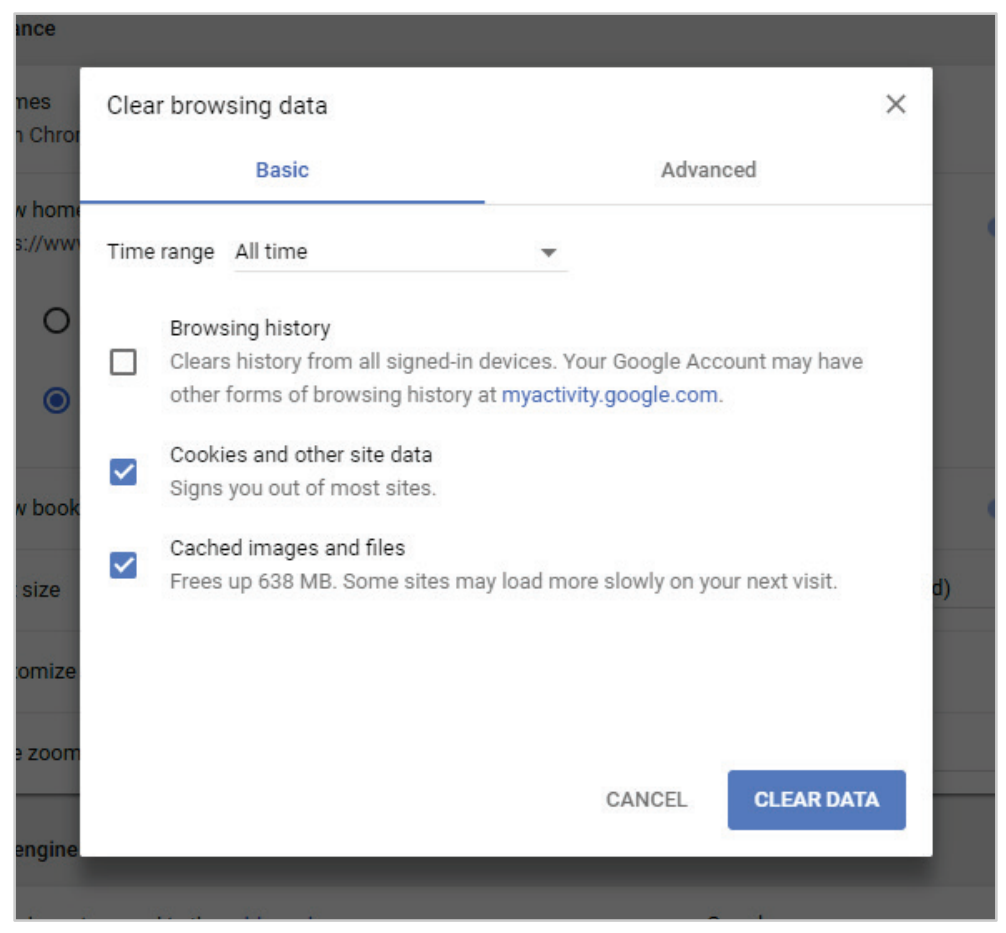

\section{Reset PIN cache}

Resetting PIN cache refers to the resetting the CAC PIN information the user has previously entered when attempting to authenticate with the SSO system. Always attempt to clear browser cache before resetting PIN cache.

To reset PIN cache, close all browser windows, remove the CAC from the reader, reinsert the $\mathrm{CAC}$ into the reader, then restart the browser. On rare occasions, the user may have to repeat all steps and reboot their computer for the issue to be resolved. 


\section{Appendix C: Points of Contact}

Tisa Webb

Office of Research and Technology Transfer (ORTT)

601-634-4259

Antisa.C.Webb@usace.army.mil

Marty Garton

Information Technology Laboratory (ITL)

601-634-2888

Byron.M.Garton@erdc.dren.mil

Sage Broderick

Information Technology Laboratory (ITL)

601-634-2821

Sage.Broderick@erdc.dren.mil

Michael Clement

Information Technology Laboratory (ITL)

601-631-5138

Michael.A.Clement@erdc.dren.mil 


\section{Acronyms and Abbreviations}

$\begin{array}{ll}\text { ACE-IT } & \text { Army Corps of Engineers Information Technology } \\ \text { CAC } & \text { Common Access Card } \\ \text { CMS } & \text { Content Management System } \\ \text { DoD } & \text { Department of Defense } \\ \text { ERDC } & \text { Engineer Research and Development Center } \\ \text { IP } & \text { Internet Protocol } \\ \text { ITL } & \text { Information Technology Laboratory } \\ \text { ORTT } & \text { Office of Research and Technology Transfer } \\ \text { PIN } & \text { Personal Identification Number } \\ \text { RDE } & \text { Research and Development Environment } \\ \text { SSO } & \text { Single Sign On } \\ \text { URL } & \text { Uniform Resource Locator }\end{array}$




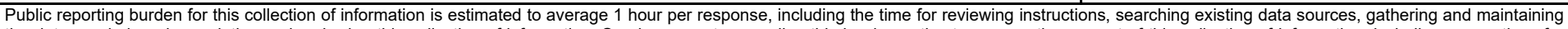

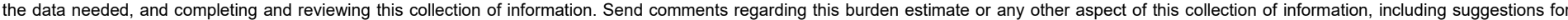

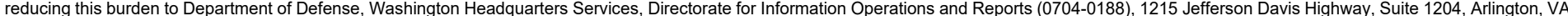

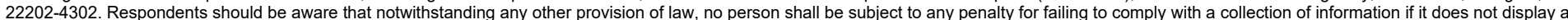
currently valid OMB control number. PLEASE DO NOT RETURN YOUR FORM TO THE ABOVE ADDRESS.
1. REPORT DATE (DD-MM-YYYY) 2. REPORT TYPE
3. DATES COVERED (From - To)

September 2020 Final

4. TITLE AND SUBTITLE

Discover ERDC Knowledge Management Representative (KMR) User's Guide

5a. CONTRACT NUMBER

5b. GRANT NUMBER

5c. PROGRAM ELEMENT NUMBER

\section{AUTHOR(S)}

5d. PROJECT NUMBER

Byron M. Garton, Jonathan S. Broderick, and Michael A. Clement

5e. TASK NUMBER

5f. WORK UNIT NUMBER

\section{PERFORMING ORGANIZATION NAME(S) AND ADDRESS(ES)}

Information Technology Laboratory

U.S. Army Engineer Research and Development Center

3909 Halls Ferry Road

8. PERFORMING ORGANIZATION REPORT NUMBER

Vicksburg, MS 39180-6199

\section{SPONSORING / MONITORING AGENCY NAME(S) AND ADDRESS(ES)}

10. SPONSOR/MONITOR'S ACRONYM(S)

ERDC Office of Research and Technology Transfer (ORTT)

3909 Halls Ferry Road

Vicksburg, MS 39180-6199

11. SPONSOR/MONITOR'S REPORT

NUMBER(S)

\section{DISTRIBUTION / AVAILABILITY STATEMENT}

Approved for public release; distribution is unlimited.

\section{SUPPLEMENTARY NOTES}

ERDC Office of Research and Technology Transfer (ORRT), MIPR WIC 19F1H5

\section{ABSTRACT}

Knowledge management plays a vital role in the successful execution on research projects at the U.S. Army Engineer Research and Development Center (ERDC). Accumulating and building upon knowledge is the cornerstone of the research and development process. Maintaining and providing access to knowledge is essential to the successful execution of research programs. An initiative to improve access to knowledge and the tools available to researchers was started by the Office of Research and Technology Transfer (ORRT). The result of that initiative is a knowledge portal called Discover ERDC.

This document provides a detailed look on maintaining content on the Discover ERDC site from a Knowledge Management

Representative viewpoint, and how help can be provided to those assigned to manage the content.

\section{SUBJECT TERMS}

Engineer Research and Development Center (U.S.)-- Research and development projects

\section{SECURITY CLASSIFICATION OF:}

\section{a. REPORT}

Unclassified

\section{b. ABSTRACT}

Unclassified
Web applications

Knowledge management 